\title{
Mission to Planet Earth: The First Two Billion Years
}

\author{
E.E. Stüieken ${ }^{1,2} \cdot$ S.M. Som ${ }^{3}$ M. Claire ${ }^{1,2,3}$. \\ S. Rugheimer ${ }^{4}$ - M. Scherf ${ }^{5}$ - L. Sproß ${ }^{5,6} \cdot$ N. Tosi ${ }^{7,8}$. \\ Y. Ueno ${ }^{9,10}$ • H. Lammer ${ }^{6}$
}

Received: 14 July 2019 / Accepted: 25 February 2020 / Published online: 16 March 2020

(C) The Author(s) 2020

\begin{abstract}
Solar radiation and geological processes over the first few million years of Earth's history, followed soon thereafter by the origin of life, steered our planet towards an evolutionary trajectory of long-lived habitability that ultimately enabled the emergence of complex life. We review the most important conditions and feedbacks over the first 2 billion years of this trajectory, which perhaps represent the best analogue for other habitable worlds in the galaxy. Crucial aspects included: (1) the redox state and volatile content of Earth's building blocks, which determined the longevity of the magma ocean and its ability to degas $\mathrm{H}_{2} \mathrm{O}$ and other greenhouse gases, in particular $\mathrm{CO}_{2}$, allowing the condensation of a water ocean; (2) the chemical properties of the resulting degassed mantle, including oxygen fugacity, which would have not only affected its physical properties and thus its ability to recycle volatiles and nutrients via plate tectonics, but also contributed to the timescale of atmospheric oxygenation; (3) the emergence of life, in particular the origin of autotrophy, biological $\mathrm{N}_{2}$ fixation, and oxygenic photosynthesis, which accelerated sluggish abiotic pro-
\end{abstract}

Reading Terrestrial Planet Evolution in Isotopes and Element Measurements

Edited by Helmut Lammer, Bernard Marty, Aubrey L. Zerkle, Michel Blanc, Hugh O’Neill and Thorsten Kleine

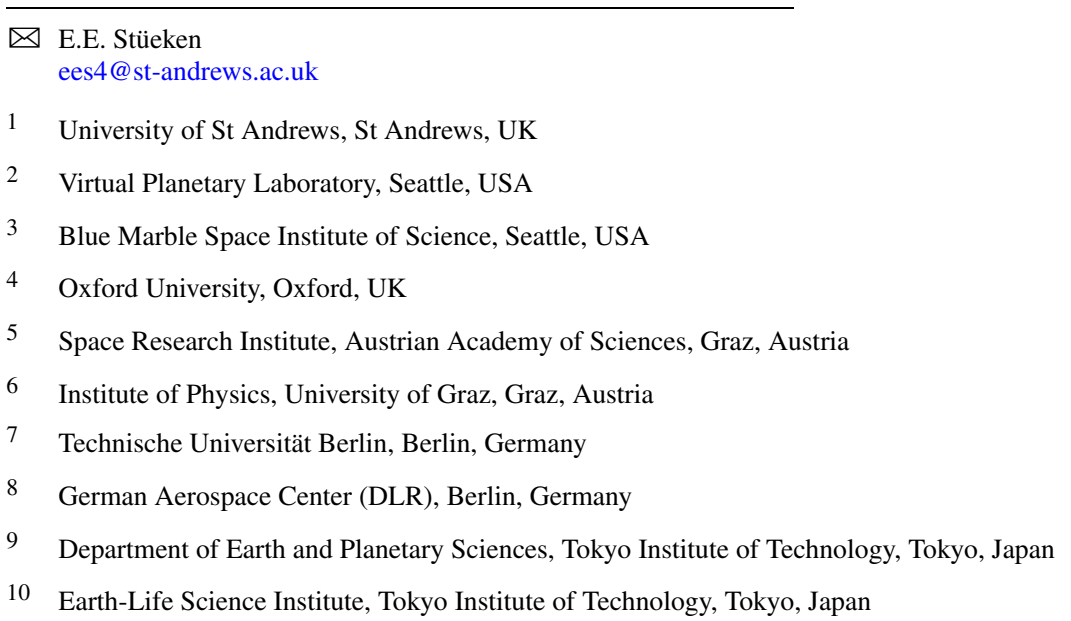


cesses of transferring some volatiles back into the lithosphere; (4) strong stellar UV radiation on the early Earth, which may have eroded significant amounts of atmospheric volatiles, depending on atmospheric $\mathrm{CO}_{2} / \mathrm{N}_{2}$ ratios and thus impacted the redox state of the mantle as well as the timing of life's origin; and (5) evidence of strong photochemical effects on Earth's sulfur cycle, preserved in the form of mass-independent sulfur isotope fractionation, and potentially linked to fractionation in organic carbon isotopes. The early Earth presents itself as an exoplanet analogue that can be explored through the existing rock record, allowing us to identify atmospheric signatures diagnostic of biological metabolisms that may be detectable on other inhabited planets with next-generation telescopes. We conclude that investigating the development of habitable conditions on terrestrial planets, an inherently complex problem, requires multi-disciplinary collaboration and creative solutions.

Keywords Early Earth · Biosignatures · Atmospheric evolution

\section{Introduction}

Earth is the only inhabited planet that we know of. Our planet therefore provides a key anchor point for understanding, predicting, and modelling the formation of habitable worlds as well as for testing remote and in situ biosignatures. Importantly, Earth and its biosphere have undergone major evolutionary changes over the last 4.5 billion years, enabling the investigation of geo-biological feedbacks under a range of environmental conditions. Until about 2.4 billion years ago $(\mathrm{Ga})$ Earth's atmosphere was essentially devoid of $\mathrm{O}_{2}$ gas. Complex life only evolved roughly 600 million years ago (Ma). For its first two billion years (4.5$2.5 \mathrm{Ga}$ ), ecosystems were thus dominated by anaerobic microbial communities and perhaps more strongly tied to planetary processes than today. These processes include outgassing of volatiles, recycling of nutrients and greenhouse gases after the establishment of plate tectonics, and photochemical reactions that can erode atmospheric gases or convert them into soluble molecules. Life originated from this framework and eventually took control over many of the associated feedbacks. It is this interval of Earth's history that can perhaps be considered the best analogue for other worlds that may be inhabited by simple life forms, incapable of complex metabolisms such as oxygenic photosynthesis. This paper reviews what is known about the establishment of habitable conditions spanning geological (Sects. 2, 3), biological (Sect. 4), solar/photochemical constraints (Sects. 5, 6, 7) on the atmosphere; and how these feed into the frontier challenge of detecting biospheres remotely via atmospheric signatures (Sect. 8).

\section{From Magma to a Water Ocean}

An important transition towards habitability in Earth's early history was the establishment of a liquid water ocean under an atmosphere with a stabilizing degree of greenhouse warming. This transition required cooling and solidification of the primitive mantle following Moon formation (Lock et al. 2018; Canup and Asphaug 2001), as well as outgassing of $\mathrm{H}_{2} \mathrm{O}$ and $\mathrm{CO}_{2}$ (Elkins-Tanton 2008). These two volatiles were perhaps the major players of the socalled secondary atmosphere from which the ocean ultimately condensed. The formation period of a solid crust following Moon formation and its duration are crucial for understanding the initial secondary atmospheres on Earth-like planets. During the solidification 
period of the primitive mantle, volatiles are relatively easily exchanged between the planetary interior and the atmosphere. Once the surface solidifies to form the crust, this exchange is severely hampered for the rest of the planet's lifetime, causing volatile exchange rates to drop dramatically. In the classical scenario of a magma ocean that crystallizes from the bottom upwards (e.g. Elkins-Tanton 2012), some volatile components can become supersaturated in the magma and be released into the atmosphere. By this mechanism, most of the $\mathrm{CO}_{2}$ tends to be outgassed in the earliest stages of the magma ocean because of its low solubility in silicate melts. $\mathrm{H}_{2} \mathrm{O}$, in contrast, is more soluble and is outgassed only when it is highly enriched in the liquid magma ocean-a condition that is generally reached towards the end of magma solidification. At that time, atmospheric $\mathrm{CO}_{2}$ and $\mathrm{H}_{2} \mathrm{O}$ may have reached partial pressures $\left(p_{\mathrm{CO}_{2}}, p_{\mathrm{H}_{2}}\right)$ of approximately 100 bar and a few hundred bar, respectively (Zahnle et al. 1988; Schaefer and Fegley 2010; Sleep 2010; Salvador et al. 2017). All outgassed particles, in combination with possible remnants from the hydrogen envelope that formed during the planet's accretion phase (the "primary atmosphere"), form a dense steam atmosphere.

The behaviour of nitrogen in this period, the most abundant atmospheric component at present day, is not fully understood. On the one hand, several mass-balance and modelling studies have suggested $\mathrm{N}_{2}$ partial pressures similar to today or slightly higher (e.g. Barry and Hilton 2016; Stüeken et al. 2016b; Johnson and Goldblatt 2018; Mallik et al. 2018). In fact, higher-than-modern atmospheric $p_{\mathrm{N}_{2}}$, paired with relatively low $p_{\mathrm{CO}_{2}}$, was proposed as a potential solution to the Faint Young Sun Paradox later in the Archean by pressure broadening (e.g. Goldblatt et al. 2009; Goldblatt and Zahnle 2011; Byrne and Goldblatt 2015). On the other hand, in an atmospheric steam $\mathrm{N}_{2}$ could have been reduced to $\mathrm{NH}_{3}$ which may have been soluble in the magma ocean. Through this mechanism, nitrogen could thus have been transferred efficiently from the atmosphere back into the lithosphere as long as the magma ocean was liquid (Solomatov 2000; Libourel et al. 2003; Zahnle et al. 2010; Kadik et al. 2011; Wordsworth 2016). In addition to this temperature-driven conversion of $\mathrm{N}_{2}$ to $\mathrm{NH}_{3}$ at the interface between the atmosphere and the crust, high EUV irradiation from the young Sun (e.g. Tu et al. 2015; Airapetian et al. 2016), cosmic rays (e.g. Grenfell et al. 2012; Tabataba-Vakili et al. 2016; and see also Sect. 5), and frequent meteoric impacts (e.g. Fegley et al. 1986; Parkos et al. 2018) are all capable of dissociating atmospheric $\mathrm{N}_{2}$ and enabling $\mathrm{N}$ incorporation into surface materials. Although significant uncertainties remain, emerging views on ingassing and escape of $\mathrm{N}$ allow for depletion of $\mathrm{N}$ (and potentially other volatiles) in Earth's early secondary atmosphere.

If nitrogen was outgassed during the magma ocean phase with a similar $\mathrm{C} / \mathrm{N}$ ratio as observed on present Earth and did not escape, then the partial pressure of $\mathrm{N}_{2}\left(p_{\mathrm{N}_{2}}\right)$ is expected to be two orders lower than that of $\mathrm{CO}_{2}$. It would not exceed $500 \mathrm{mbar}$ for realistic amounts of $\mathrm{CO}_{2}$ (Lammer et al. 2019). Following the estimates of abiotic lightning-driven $\mathrm{N}_{2}$ fixation rates proposed by Navarro-González et al. (1998), and assuming complete conversion of this fixed nitrogen to $\mathrm{NH}_{3}$, this partial pressure would imply a drawdown of 100 mbar nitrogen in around $5 \mathrm{Myr}$ assuming that the fixed nitrogen is trapped as $\mathrm{NH}_{3}$ at reducing conditions in the mantle and is not outgassed until the mantle reaches a high enough oxidation state for the conversion of $\mathrm{NH}_{3}$ to $\mathrm{N}_{2}$ (discussed in Lammer et al. 2019). However, it remains uncertain if nitrogen outgassed at all during the magma ocean stage (Libourel et al. 2003). In summary, it is thus conceivable that nitrogen partial pressures were rather low towards the end of the Hadean, but outgassing rates during the early Earth remain a crucial unknown.

The $\mathrm{H}_{2} \mathrm{O}$ and $\mathrm{CO}_{2}$ that outgassed from the magma ocean would have acted as greenhouse gases. $\mathrm{H}_{2} \mathrm{O}$ in particular absorbs infrared radiation over a wide range of wavelengths, which may have slowed down the cooling and solidification of the magma ocean (Elkins-Tanton 
Fig. 1 Composition of outgassed gases from a magma ocean in dependence of oxidation state and temperature. The gas has a fix $\mathrm{H} / \mathrm{C}$ ratio of 0.5 . IW describes the oxygen fugacity through the buffer in coexisting pure iron and wüstite (figure by Hirschmann 2012)

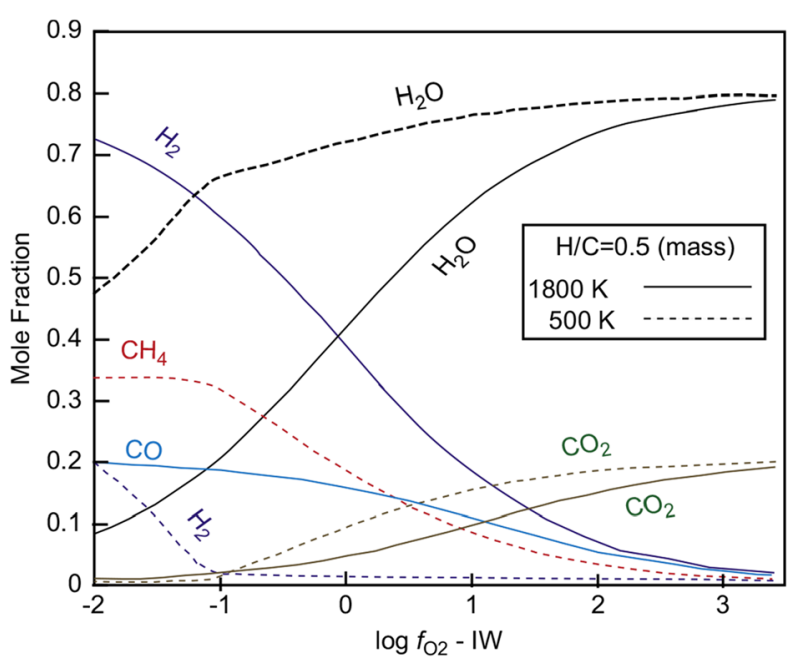

2008, 2012). Although the solidification timescale depends on several poorly constrained parameters (Nikolaou et al. 2019), it is influenced to first order by the bulk abundance of volatiles and by the incoming stellar radiation (Hamano et al. 2013; Lebrun et al. 2013; Nikolaou et al. 2019). A volatile-depleted magma ocean that radiates its heat to space in the absence of an atmosphere is expected to solidify relatively quickly within a few thousand years (e.g. Monteux et al. 2016). In contrast, a magma ocean with a conservative initial $\mathrm{H}_{2} \mathrm{O}$ budget equivalent to 300 bar outgasses about 220 bar $\mathrm{H}_{2} \mathrm{O}$ into the atmosphere over its evolution, and at a distance from the Sun of $1 \mathrm{AU}$, such an atmosphere extends the solidification time to about 1 Myr (e.g. Lebrun et al. 2013; Nikolaou et al. 2019). This duration scales roughly linearly with the initial abundance of water in the mantle, which is poorly constrained (Korenaga 2013). Since these timescales are relatively short compared to the period over which large-scale, magma-ocean-forming collisions with other planetary bodies are expected, the occurrence of multiple magma ocean phases is possible over the early planetary history. Indeed, for the Earth, two episodes of magma ocean outgassing have been proposed to explain the isotopic difference of ${ }^{3} \mathrm{He} /{ }^{22} \mathrm{Ne}$ between the depleted mantle and a primitive deep reservoir (Tucker and Mukhopadhyay 2014). It has to be noted that the oxidation state of the melts has a crucial influence on the outgassed composition (see Fig. 1).

The end of the magma ocean is usually identified as the time when the planet enters a so-called "mush phase" (Lebrun et al. 2013), where the whole mantle up to its surface exhibits a solid-like behavior despite the presence of residual melt (below 30-40\%) at shallow depths. The beginning of the mush phase coincides with a dramatic drop in the surface temperature and heat flux, which generally causes part of the outgassed steam atmosphere to condense, forming a water ocean. The possibility to achieve condensation depends on the amount of $\mathrm{CO}_{2}$ present in the atmosphere at the end of solidification (Lebrun et al. 2013; Massol et al. 2016; Salvador et al. 2017). For a given amount of outgassed water, the higher the $\mathrm{CO}_{2}$ partial pressure, the more difficult it is to achieve condensation, which occurs when the saturation vapor pressure of water at the surface is reached. At the Earth's orbit and for plausible amounts of $\mathrm{H}_{2} \mathrm{O}$ and $\mathrm{CO}_{2}$ (comparable to the present-day extent of the two reservoirs), the condition to achieve condensation is easily met (e.g. Salvador et al. 2017). 
The formation of a water ocean is thus a natural outcome of the solidification of a waterrich magma ocean and is expected to occur within up to few million years after the last major impact event capable of causing large-scale mantle melting. The last such event was probably the Moon-forming impact taking place up to $130 \mathrm{Myr}$ after the condensation of the first solids in the solar system (e.g. Jacobson et al. 2014; Bottke et al. 2015). The closeto-chondritic $\mathrm{D} / \mathrm{H}$ ratio of sea water provides evidence that the oxidation of silicate Earth occurred during or before the crystallization of the final global-scale magma ocean (Pahlevan et al. 2019, see Fig. 1). If the mantle had been highly reducing at that time, then the outgassed atmosphere would have been dominated by $\mathrm{H}_{2}$ and $\mathrm{CO}$ instead of $\mathrm{H}_{2} \mathrm{O}$ and $\mathrm{CO}_{2}$, and such a gas mixture would have facilitated hydrogen escape to space, including loss of $\mathrm{H}$ relative to $\mathrm{D}$, leading to higher $\mathrm{D} / \mathrm{H}$ ratios than observed. $\mathrm{D} / \mathrm{H}$ ratios thus suggest that the silicate Earth was at least oxidized enough to outgas mainly $\mathrm{H}_{2} \mathrm{O}$ and $\mathrm{CO}_{2}$, leading to reduced hydrogen escape, because of $\mathrm{CO}_{2}$ would have provided IR-cooling in the upper atmosphere. Similarly, if the steam atmosphere had survived for several Myr, one would expect to see a more significant increase in the $\mathrm{D} / \mathrm{H}$ ratio through hydrodynamic escape over time. Hence the present-day $\mathrm{D} / \mathrm{H}$ ratio implicates a short-lived steam atmosphere presence. This view is further supported by unfractionated $\mathrm{Ne}$ isotopes (Avice and Marty 2020, this issue).

$\mathrm{CO}_{2}$ would have played a key role in protecting the secondary atmosphere from escaping to space, because it cools the upper atmosphere and therefore reduces its expansion. For sufficient atmospheric $\mathrm{CO}_{2}$, an appropriate oxidation state of the final magma ocean is required (Fig. 1); for reduced conditions the atmosphere is therefore highly susceptible to strong escape rates (Kasting 1982; Lammer et al. 2018). After the magma-ocean phase and during ensuing tectonic conditions that may have been similar to a stagnant-lid regime (e.g. O'Neill and Debaille 2014), $\mathrm{CO}_{2}$ would have dissolved in the ocean and reacted with oceanic crust as in classic weathering reactions. This process would have decreased the partial pressure $\mathrm{CO}_{2}$ over time (e.g. Hessler et al. 2004; Kanzaki and Murakami 2015; Sleep and Zahnle 2001). For 1 bar of atmospheric $\mathrm{CO}_{2}$, in the presence of a stagnant-lid and a water ocean, estimates of the amount of $\mathrm{CO}_{2}$ that could have been removed by seafloor weathering range from 70 to $97 \%$ (Walker 1985; Jacob 1999). With the onset of plate tectonics, which allowed replacement of weatherable surface material, $\mathrm{CO}_{2}$ levels would likely have been reduced further. Hence overall, atmospheric $p_{\mathrm{CO}_{2}}$ likely decreased continuously throughout the Archean, especially if volcanic regimes did not change significantly during this time to counteract high weathering rates, but this remains unconstrained. As discussed in Birmingham et al. (2020, this issue), the young Sun's bolometric luminosity was only about $70 \%$ of today's value, which demands higher amounts of greenhouse gases like $\mathrm{CO}_{2}$, $\mathrm{CH}_{4}$, etc. to keep the ocean liquid (Feulner 2012; Wolf and Toon 2013; Kunze et al. 2014; Charnay et al. 2017).

A high $\mathrm{CO}_{2}$ to $\mathrm{N}_{2}$ ratio in the early Archean was proposed by Lammer et al. (2019): High EUV radiation likely eroded $\mathrm{N}_{2}$ from the atmosphere, but since there is no detectable evidence of this process in the ${ }^{14} \mathrm{~N} /{ }^{15} \mathrm{~N}$ record (Füri and Marty 2015), the atmospheric $\mathrm{N}_{2}$ reservoir was probably small at that time and only constituted a small fraction of Earth's total nitrogen inventory. However, sometime in Earth's history, maybe as late as the Great Oxidation Event at $2.4 \mathrm{Ga}$, nitrogen became the most abundant constituent in the atmosphere, possibly due to continuous volcanogenic or biogenic $\mathrm{N}_{2}$ liberation (Zerkle et al. 2017; Lammer et al. 2019; Stüeken et al. 2016b), although see Sect. 3.2. By that time, solar EUV irradiation would have been sufficiently low and the magnetosphere sufficiently intense and stable to minimize strong atmospheric escape of nitrogen, as supported by stable isotopic compositions in atmospheric $\mathrm{N}_{2}$ since that time (Marty et al. 2013). 


\section{Beyond the Magma Ocean: Geological Controls on Planetary Surface Evolution}

The development of habitable conditions at the Earth's surface was controlled by geological parameters, i.e. the redox state and composition of the primitive mantle and the internal heat of the planet (Sect. 2). While the details of these processes provided the initial conditions that enabled the evolution of the Earth system, additional processes were pivotal in establishing the habitability of our planet and may prove fundamental to the search for life in the Universe. A clear impediment to this line of research is the scarcity of a preserved geologic record of Earth's most ancient history. As a result, the state of the early Earth is predominantly investigated through numerical simulations. Two types of models are in use: (a) understanding the controls on the modern Earth and seeking how these contributions have changed backwards in time ("backward models"), and (b) developing initial conditions bounded by fundamental physical and chemical laws (Sleep 2010) and evolving these simulations forward in time ("forward models").

A planetary state can be thought of as a snapshot of a planet at a certain instant of time. The planetary state of modern Earth is determined by the transfer of energy between the planet's interior and the planet's surface, coupled with the transfer of energy between the planet's surface and the space environment. As a result, the state of Earth's surface depends on energy delivered from the Earth's interior and from the Sun (Lenardic et al. 2016). The Earth's interior has a comparatively greater role than the Sun in determining Earth's state for two main reasons: The first is in the delivery and recycling of volatiles to and from the atmosphere by way of plate tectonics (mantle convection and plate subduction) and associated volcanism, and the second is the protection of the atmosphere from solar wind stripping through the magnetic field generated by convection of the liquid outer core.

\subsection{Earth Formation, Ocean Evolution, and the Onset of Plate Tectonics}

The proto-Earth formed by the accretion of smaller precursors analogues of which still exist today as remnants of the early solar system: chondritic meteorites ("chondrites"). The EarthMoon system was likely formed following a high-energy high-angular-momentum impact between the proto-Earth and "Theia", another solar system body. This cataclysmic impact may have formed a synestia, a rapidly spinning mass of vaporized rock from which the Earth-Moon system emerged (Lock et al. 2018). This proposed mechanism differs from the canonical model of the "Moon-forming impact" based on smooth particle hydrodynamics (Canup and Asphaug 2001). In the latter mechanism, forward models predict a hydrated initial mantle (Zahnle et al. 2010). Backward models argue for a dry mantle (Korenaga 2011). Regardless of the initial state of the mantle, the resulting angular momentum at the end of the synestia or canonical Moon-forming impact is hypothesized to have been conserved since then.

As a result of the tidal torque on the Earth's ocean by the Moon and by conservation of angular momentum, the Earth's rotation rate has been slowing down and the Moon has receded. Orbital mechanics calculations suggest an Earth spinning twice the current rate 3.5 billion years ago (Webb 1982). Such predictions mostly agree with geological indicators of the diurnal cycle (Williams 2000). Any predictions older than 3.5 Ga must be used with caution as the uncertainties in the controlling parameters become high. For example, the origin and initial evolution of the oceans, a major player in tidal dissipation (Bills and Ray 1999), is poorly constrained. Based on geochemical arguments, the oceans' volume has been proposed to be $26 \%$ larger 3.8 billion years ago, slowly losing mass through $\mathrm{H}_{2} \mathrm{O}$ 
dissociation and hydrogen escape (Pope et al. 2012). Other studies suggests an ocean 50\% larger 3.0 billion years ago, based on assumptions about the thermal evolution of the Earth and constancy of the continental freeboard, which states that the mean sea-level has always been close to the mean continental level (Korenaga 2013). Ocean salinity was likely similar or slightly (30\%) higher than modern values (Marty et al. 2018; Sleep 2010). How a larger ocean would have affected tidal dissipation is unclear. A much faster spinning planet would have had dynamical implications for the atmosphere, for example thinning the latitudinal extent of the Hadley cell among other properties sensitive to the Coriolis force (Held and Hou 2002).

The atmospheric volatile evolution of modern Earth is strongly controlled by plate tectonics, mantle redox and outgassing rates. How outgassing rates scale with geothermal heat flux remains poorly constrained. Subduction carries sediments that contain atmospheric volatiles into the mantle, from where they can be speciated and either stored in the mantle wedge or released back into the atmosphere via volcanism. Mantle redox can control the oxidation state of released volatiles (Trail et al. 2011; Mikhail and Sverjensky 2014) coupled with hydrogen escape following methane photolysis on early Earth (Catling et al. 2001). The oxidation state of the atmosphere is thus coupled to that of the mantle (Nicklas et al. 2019), emphasizing the role of the planetary interior in affecting the planetary state. Oxygen fugacity $\left(\mathrm{fO}_{2}\right)$ investigations of Precambrian lavas reveal a secular oxidation of the mantle from $3.5 \mathrm{Ga}$ to $1.9 \mathrm{Ga}$. No single process explains this oxidation, with recycling of altered oceanic crust, venting of oxygen from the core due to inner core crystallization, and convection-driven homogenization of an initially redox-heterogeneous primordial mantle as the proposed end-member contributors (Nicklas et al. 2019).

Predictions of past behavior of atmospheric volatiles, such as $\mathrm{C}$ and $\mathrm{N}$ have been performed predominantly via box modeling (Hart 1978). Such efforts necessarily require assumptions that become harder to defend in deep time, especially prior to $\sim 3 \mathrm{Ga}$. Common first-order assumptions include that the same mechanism of mantle recycling has existed over geological history and that arc and ridge fluxes scale with the heat production of the radioactive elements that fuel Earth's interior. Other important parametrizations include the known luminosity changes of our Sun as stars increase in luminosity as they age (Gough 1981), which contributes to surface temperature and thus weathering rates of $\mathrm{C}$ and $\mathrm{N}$ (Walker et al. 1981). However, the assumed coupled history between tectonic regime and planetary heat flux is far from settled (Lenardic et al. 2016), with suggestions regarding the initiation of modern plate tectonics regime spanning the geological record (Korenaga 2013; Sleep and Schubert 2007).

Observational insights on the thermal evolution of the Earth do exist. Herzberg et al. (2010) computationally predict the $\mathrm{MgO}$ and $\mathrm{FeO}$ content of the primary magmas responsible for basaltic rocks spanning Earth history. These chemical parameters are a function of mantle temperature. They find a maximum $T$ of $\sim 1500-1600{ }^{\circ} \mathrm{C}$ (compared to a modern value of $1350{ }^{\circ} \mathrm{C}$ ) at 2.5-3.0 Ga. Mantle recycling with subduction is inferred from $2.7 \mathrm{Ga}$ rocks. Continental rifting has also been proposed as far back as 3.2 Ga (Van Kranendonk et al. 2007). Several plate tectonic models fit these constraints, and the correct one may ultimately depend on advances in knowledge regarding the interaction of the ocean and the mantle over Earth history and on additional geological constraints.

Taken together, a heuristic model can be presented if we assume that the ocean volume has indeed decreased over time to the present value. Based on evidence from ancient zircons, primordial oceans appear to have existed by $4.3 \mathrm{Ga}$ (Ushikubo et al. 2008). Such primordial oceans, formed by the collapse of a steam atmosphere, could have been underlain by a dry mantle (Korenaga 2013). The water would act to weaken the previously stiff lithosphere (akin to present-day Venus), and a dry mantle would lead to high convective stress. 
Modern-style subduction was initiated when convective stresses overcame the strength of the lithosphere (plates), but initiation may have been delayed. Distinct geodynamic regimes compared to modern plate tectonics are inferred at $4 \mathrm{Ga}$ from zircon geochemistry (Reimink et al. 2016).

It is thus plausible that subduction processes began as late as the mid-Archean (3.82.5 Ga) rather than in the Hadean (4.5-3.8 Ga) (Avice et al. 2017; Parai and Mukhopadhyay 2018; Péron and Moreira 2018).The near-surface material would have then begun to participate in mantle overturn by being dragged down. Such subduction would have started hydrating the mantle, thus increasing the viscosity contrast $(\Delta \eta)$ across the lithosphere. Because the mantle's internal Raleigh number scales with $\Delta \eta^{2}$, continued subduction would have further promoted convection (Korenaga 2013). Net water influx would eventually subside to reach a steady state as the ocean volume decreased and further ocean loss was limited to hydrogen escape. Initially, internal heating $(H)$ would have exceeded the mantle convective heatflux $Q(H / Q>1)$, leading to an increase in mantle temperature until $\sim 3$ Ga where the ratio would have flipped and Earth would then witness a slow cooling to achieve the modern Urey ratio $(U r=H / Q)$ of $\sim 0.3$. This increase in Urey ratio from the Hadean to the mid-Archean may explain the possible delay in the onset of subduction.

\subsection{Geological Sources and Sinks of Atmospheric Carbon and Nitrogen}

Atmospheric volatiles like $\mathrm{C}$ and $\mathrm{N}$ cycle through the various planetary reservoirs. Common reservoirs for $\mathrm{C}$ include the ocean/atmosphere system, the seafloor, continents, and the mantle (Sleep and Zahnle 2001; Tajika and Matsui 1992). For geological carbon cycle investigations (i.e. "long-term" cycle), biology is often omitted as the corresponding reservoir size of biota is small (Tajika and Matsui 1990), even though fluxes can be substantial (see Sect. 4.2). From the mantle, $\mathrm{C}$ can return to the ocean/atmosphere via arc and ridge volcanism. From the ocean/atmosphere, $\mathrm{C}$ can return to the mantle via precipitation of carbonate and organic carbon on the seafloor, followed by subduction. Continental weathering, which pulls $\mathrm{CO}_{2}$ out of the atmosphere through the formation of bicarbonate ions, is balanced as continents "scrape" sediments off the seafloor during subduction. This process is called accretion. The geological carbon cycle is important as a "planetary thermostat" in regulating planetary surface temperature via the greenhouse effect driven by $p_{\mathrm{CO}_{2}}$ (Walker et al. 1981). Potentially higher levels of atmospheric $\mathrm{C}$ on the early Earth would have been driven by a higher degassing flux, itself driven by hotter mantle temperatures. However, this higher flux was perhaps balanced to some extent by faster plate velocities and corresponding faster subduction rates resulting from the higher heat production.

The $\mathrm{N}$ cycle can be assessed using a similar framework, yet $\mathrm{N}$ cycle studies are in their infancy compared with the abundance of work on the $\mathrm{C}$ cycle. A major difference between the modern and the ancient $\mathrm{N}$ cycle is the oxidized nature of modern Earth. For modern Earth, a quantitative flux balance can be written (Som et al. 2016). The total N source flux $(0.33 \pm 0.08 \mathrm{Tmol} / \mathrm{year})$, composed of volcanic outgassing $(0.18 \pm 0.07 \mathrm{Tmol} / \mathrm{year})$ and oxidative weathering $(0.15 \pm 0.03)$ balances the total $\mathrm{N}$ sink flux composed entirely of $\mathrm{N}$ burial $(0.4 \pm 0.2 \mathrm{Tmol} / \mathrm{year})$. The subducted flux can essentially be ignored as it is within the uncertainty $(0.094 \pm 0.015 \mathrm{Tmol} /$ year $)$.

On the ancient Earth, oxygen was essentially absent from the environment (Reinhard et al. 2016). Given the flux balance above, oxidative weathering can thus be neglected, dropping the $\mathrm{N}_{2}$ source flux to $50 \%$ of its present value, if all other fluxes remained constant (Som et al. 2016). At steady state, the global $\mathrm{N}$ sink would balance the source flux and be likewise diminished. Assuming that the atmospheric $\mathrm{N}$ reservoir is proportional to source 
and sink fluxes, a 50\% reduction in the $\mathrm{N}$ source would leave the atmospheric reservoir depleted by $50 \%$ compared to modern values. Given that the modern air pressure is composed of 0.8 bar $\mathrm{N}_{2}$, and 0.2 bar $\mathrm{O}_{2}$, the considerations above ( $p_{\mathrm{N}_{2}}$ of $50 \%$ of 0.8 bar) predict an Archean pressure of 0.4 bar. While this framework is first-order and neglecting potential non-linearities in the flux-reservoir relationship, low air pressure has been corroborated by independent constraints from the Archean rock record (Avice et al. 2018; Endo et al. 2019; Marty et al. 2013; Som et al. 2012, 2016). Additional considerations for the Archean include the existence of ammonium in the ocean as a sink for $\mathrm{N}$ via ion replacement in clays that are eventually subducted (Stüeken et al. 2016b), and redox controls on $\mathrm{N}_{2}$ volcanic outgassing (Mikhail and Sverjensky 2014).

Taken together, a heuristic model of $\mathrm{N}$ evolution can be presented. The rocky Earth started with a dense $\mathrm{CO}_{2} / \mathrm{H}_{2} \mathrm{O}$ atmosphere with perhaps lesser amounts of $\mathrm{N}_{2}$ (Sleep 2010; Zahnle et al. 2010). $\mathrm{H}_{2} \mathrm{O}$ condensed out to form the oceans, and life perhaps took a foot-hold early (Sect. 4). The growing biomass soon outpaced the ability of abiotically produced fixed nitrogen to provide the biologically available nitrogen needed for biochemistry (NavarroGonzález et al. 2001a, 2001b). Under this environmental pressure, and assuming no other limiting nutrients (Zerkle 2018), biology capable of undergoing nitrogen fixation would be selected for. Indeed, nitrogen fixation is known to be an ancient metabolic pathway (Raymond et al. 2004; Sect. 4.3). In the absence of oxygen, ammonium rather than nitrate would have been the dominant nitrogen species in the ocean (Zerkle et al. 2017). Ionic substitution with potassium in clay minerals $\left(\mathrm{NH}_{4}^{+} \leftrightarrow \mathrm{K}^{+}\right)$within sedimentary pore waters would have led to burial and eventual subduction of N (Som et al. 2016; Stüeken et al. 2016b). At steady state, $\mathrm{N}$ burial may have balanced the volcanic flux. With the advent of oxygen in the environment, new processes enabled the atmospheric $\mathrm{N}$ reservoir to increase to modern values. Oxidative weathering would have introduced a new source of $\mathrm{N}$ into the atmosphere, and subducted oxidized sediments may have changed the redox state of the mantle wedge and further enabled $\mathrm{N}_{2}$ outgassing (Mikhail and Sverjensky 2014). Advances in N-cycle modeling (Johnson and Goldblatt 2018) coupled with the development of additional geological markers of air density (Goosmann et al. 2018; Silverman et al. 2018) will test this model.

\section{Biological Imprints on the Early Atmosphere}

Geological and photochemical processes set the stage for habitable conditions (Sects. 2, $3,5)$, but the emergence of life likely had a significant impact on volatile inventories of the atmosphere and solid Earth with implications for global climate and habitability (e.g., Lenton 1998). Apart from the noble gases, all atmospheric constituents, including $\mathrm{N}_{2}$ and $\mathrm{O}_{2}$, as well as the major greenhouse gases $\mathrm{CO}_{2}, \mathrm{CH}_{4}$ and $\mathrm{N}_{2} \mathrm{O}$, have biological sources and sinks. Determining the antiquity and evolution of these biological fluxes-against a backdrop of abiotic processes - is therefore important for reconstructing the habitability of the early Earth as an analogue for other worlds.

\subsection{The Surficial Carbon Cycle and the Role of Prebiotic Reactions}

To first order, the major fluxes even in the modern carbon cycle are not directly dependent on biology. Atmospheric carbon is sourced from volcanic outgassing of $\mathrm{CO}_{2}$, and it is ultimately removed by the burial of carbonate rocks. Burial of organic carbon constitutes a relatively minor fraction of around 15-20\% (Mason et al. 2017). Although many carbonate deposits today are biogenic in origin, it is conceivable that they would also form on 
an abiotic planet once carbonate minerals reach saturation in seawater. Indeed, aragonitic crystal fans from the Archean rock record have been taken as evidence for widespread abiotic carbonate precipitation in the early ocean under a $\mathrm{CO}_{2}$-rich atmosphere (Grotzinger and Kasting 1993). However, biological activity still has a significant effect on the carbon cycle, because it changes the redox state of gaseous and sedimentary carbon. Autotrophic organisms convert $\mathrm{CO}_{2}$ with a $+\mathrm{IV}$ oxidation state into organic matter or methane $\left(\mathrm{CH}_{4}\right)$ with oxidation states of 0 and $-\mathrm{IV}$, respectively. Burial of organic matter in sediments thus removes a reductant from the Earth's surface, rendering surface environments overall more oxidized (Catling 2014b). This process may have contributed to the rise of atmospheric $\mathrm{O}_{2}$ around the Archean-Proterozoic boundary, and it may have been the major driver of later oxygenation events in the Neoproterozoic and Paleozoic (Rothman et al. 2003; Husson and Peters 2017; Lenton et al. 2014; Butterfield 2018). In contrast, the production of biogenic methane injects a reductant into the atmosphere, which may have slowed down the accumulation of $\mathrm{O}_{2}$ (Zahnle et al. 2006) while also acting as a strong greenhouse gas. On the Archean Earth, where the Sun was fainter, biogenic $\mathrm{CH}_{4}$ production may have been important for maintaining a warm climate (Haqq-Misra et al. 2008; Arney et al. 2016). The onset of biological carbon burial (reductant removal) as well as the biological conversion of carbon into $\mathrm{CH}_{4}$ (reductant liberation and greenhouse gas production) were thus probably two key processes that shaped the long-term evolution of our planet.

Prior to the origin of life, some abiotic process would have converted $\mathrm{CO}_{2}$ into reduced organic carbon and methane. In fact, such abiotic sources of reduced carbon were probably essential for prebiotic chemical reactions that ultimately culminated in the rise of autotrophic cells. The major energy sources for the abiotic reduction of $\mathrm{CO}_{2}$ were likely geothermal heat, UV radiation, and lightning reactions. Geothermal settings have been shown to favor the production of methane, longer-chain alkanes and more complex organic molecules in both experiments and natural environments through so-called Fischer-Tropsch-type reactions (Cody 2004; Russell and Martin 2004; McCollom and Seewald 2007; Proskurowski et al. 2008). Hydrogen gas produced by serpentinization (i.e., aqueous alteration of fresh olivine and pyroxene) acts as a reductant, while metallic minerals such as sulfides, magnetite or elemental iron and nickel act as reaction catalysts. In atmospheric reactions, such catalysts are not needed, as lightning and UV radiation provide sufficient energy to produce organic carbon molecules from $\mathrm{CO}_{2}$ and $\mathrm{CH}_{4}$. The organic carbon products of $\mathrm{UV}$ reactions are $\mathrm{HCN}$ and $\mathrm{CH}_{2} \mathrm{O}$ (Zahnle 1986; Deamer 2007; Cleaves 2008), while lightning reactions have been reported to generate a variety of organic compounds, including amino acids and nucleobases (Miller 1953; Ferus et al. 2017). The magnitude of these abiotic sources of reduced organic carbon as well as its stability in the early ocean on the prebiotic Earth are not well constrained. However, it is conceivable that geothermally catalyzed reactions were relatively more abundant than today, because Earth's earliest crust was likely more mafic (Dhuime et al. 2015; Tang et al. 2016), leading to more widespread serpentinization (Smit and Mezger 2017) with the potential to produce large amounts of reduced carbon molecules.

\subsection{The Emergence and Early Diversity of Biological $\mathrm{CO}_{2}$ Fixation Pathways}

Although some form of abiotic $\mathrm{CO}_{2}$ reduction was undoubtedly present on the early Earth, the emergence of autotrophic life is evidence that these abiotic sources of reduced carbon were not large enough to sustain a significant biosphere. Hence the rise and radiation of autotrophic organisms probably caused a sharp increase in the burial flux of organic carbon. The most widely cited record of biological $\mathrm{CO}_{2}$ fixation is archived in carbon isotope ratios of sedimentary rocks (Schidlowski 2001). Enzymes favor ${ }^{12} \mathrm{C}$ over ${ }^{13} \mathrm{C}$ in specific ratios that are characteristic of their respective carbon fixation pathway. The most widespread 
pathway today is the Calvin cycle, catalyzed by the enzyme Rubisco, and ${ }^{12} \mathrm{C} /{ }^{13} \mathrm{C}$ ratios of ancient organic matter suggest that this metabolism may date back to the early Archean (Nisbet et al. 2007). The oldest (though controversial, see e.g. Whitehouse et al. 2019) records of the Calvin cycle go back to more than 3.9 billion years ago (Bell et al. 2015; Tashiro et al. 2017). These ancient records are controversial because carbon isotope fractionations can also be produced by abiotic processes that generate organic matter, such as FischerTropsch-type reactions (McCollom and Seewald 2006). More widely accepted evidence has been documented from around $3.5 \mathrm{Ga}$, where it coincides with occurrences of stromatolites and biogenic sulphur isotope fractionation (Buick 2007). Rocks of this age also preserve the oldest evidence of biological $\mathrm{CH}_{4}$ production (Ueno et al. 2006; Flannery et al. 2018; Schopf et al. 2018). Methanogenesis is driven by the acetyl-CoA pathway, and it is characterized by large isotopic fractionations imparted on the resulting $\mathrm{CH}_{4}$ and biomass (House et al. 2003). Isotopically depleted $\mathrm{CH}_{4}$ in gas inclusions in cherts from $>3.46 \mathrm{Ga}$ (Ueno et al. 2006) and isotopically light kerogen in similarly aged rocks (3.43-3.47 Ga, Flannery et al. 2018; Schopf et al. 2018) thus indicate that the Archean biosphere also contributed to the production of a major greenhouse gas. Phylogenetic studies suggest that the acetyl-CoA pathway is the most ancient $\mathrm{CO}_{2}$ fixation pathway (Fuchs 2011). Importantly, several enzymes involved in methanogenesis contain metallic catalysts similar to those that are considered to be important in driving abiotic Fischer-Tropsch-type reactions in hydrothermal settings (Russell and Martin 2004; Stüeken et al. 2013). This correlation may point to a hydrothermal origin of autotrophy on the early Earth.

By the Mesoarchean (3.2-2.8 Ga), evidence of life spans from the deep sea to continental lakes and soils (e.g. Rasmussen 2000; Nabhan et al. 2016; Homann et al. 2018; Stüeken and Buick 2018), suggesting that the biosphere was now diverse enough to colonize a range of environments and large enough to leave a recognizable imprint in the geologic record. Biological $\mathrm{CH}_{4}$ production at this time has been documented in particular from non-marine and brackish environments (Stuieken and Buick 2018). The Neoarchean perhaps saw an expansion of biological methane production as suggested by widespread occurrences of isotopically reduced organic carbon (Thomazo et al. 2009a, 2009b; Zerkle et al. 2012; Sect. 7). The lightest values are found in shallow marine and non-marine environments (Eigenbrode and Freeman 2006; Flannery et al. 2016; Stüeken et al. 2017), which may reflect biological consumption and oxidation of $\mathrm{CH}_{4}$ by methanotrophic organisms in a world that experienced increasing local (Lalonde and Konhauser 2015; Sumner et al. 2015) and/or temporal (Anbar et al. 2007; Koehler et al. 2018) oxygenation of surface environments by growing populations of oxygenic phototrophs. Biological and geological feedbacks associated with these processes ultimately led to the Great Oxidation Event (GOE) in the Paleoproterozoic (Lyons et al. 2014).

\subsection{The Nitrogen Cycle and Its Abiotic Roots}

Like carbon, nitrogen is a major constituent of all life on Earth. Its largest reservoir at the Earth's surface is atmospheric $\mathrm{N}_{2}$ gas, which is relatively inert. Roughly $15 \%$ of cultured prokaryotic organisms are capable of breaking the $\mathrm{N}_{2}$ triple bond with a so-called nitrogenase enzyme (Dos Santos et al. 2012). In this process, termed biological $\mathrm{N}_{2}$ fixation, the end product is ammonium $\left(\mathrm{NH}_{4}^{+}\right)$, the most reduced form of nitrogen. Today, the estimated global marine $\mathrm{N}_{2}$ fixation rate is on the order of $10^{11} \mathrm{~kg} / \mathrm{yr}$ (Wang et al. 2019). About half as much is fixed by terrestrial ecosystems (Vitousek et al. 2013), some of which gets transported to the ocean by rivers. However, only about $1-2 \%$ of this biologically fixed nitrogen is buried in sediments (Stuieken et al. 2016b). The majority is recycled through remineralization of biomass to nitrate $\left(\mathrm{NO}_{3}^{-}\right)$, which is subsequently reduced back to $\mathrm{N}_{2}$ in suboxic 
sedimentary pore waters and marine oxygen minimum zones (Kritee et al. 2012). Longterm removal of nitrogen from the atmosphere is therefore directly dependent on biological productivity and the efficiency of biomass burial. Within sediments, buried biomass slowly breaks down and releases ammonium into pore waters, where it can build up to millimolar concentrations (e.g., Boudreau and Canfield 1988). Ammonium has the same charge and roughly the same size as $\mathrm{K}^{+}$and can therefore partition into diagenetic potassium-rich clay minerals, such as illite (Schroeder and McLain 1998). During subsequent lithification, metamorphism and suduction, some of this silicate-bound ammonium can be stored in the continental crust and the Earth's mantle (Palya et al. 2011). Estimates suggest that the continental crust contains about half as much nitrogen as the modern atmosphere, and most of this crustal nitrogen is stored in (meta-)sedimentary rocks (Johnson and Goldblatt 2015). The contribution of biomass burial to the nitrogen reservoir in the mantle is difficult to estimate (Zerkle and Mikhail 2017), but it seems likely that biological activity has removed a significant amount of $\mathrm{N}_{2}$ from the atmosphere over time.

Although biological $\mathrm{N}_{2}$ fixation constitutes the major flux of nitrogen to seawater today, there are significant abiotic fixation fluxes, which would have dominated the nitrogen cycle prior to the emergence of life. The most important abiotic fluxes are hydrothermal reduction of $\mathrm{N}_{2}$ to $\mathrm{NH}_{4}^{+}$(Brandes et al. 1998; Smirnov et al. 2008), photochemical HCN production by UV radiation (Zahnle 1986) and volcanically or lightning-driven conversion of $\mathrm{N}_{2}$ to nitrogen oxides (mainly $\mathrm{NO}$ and $\mathrm{N}_{2} \mathrm{O}$ ) (Kasting and Walker 1981; Navarro-González et al. 1998; Mather et al. 2004), followed by reduction of nitrogen oxides to $\mathrm{NH}_{4}^{+}$with dissolved $\mathrm{Fe}^{2+}$ (Summers and Chang 1993). The magnitude of the various abiotic sources of fixed nitrogen on the early Earth has been appraised in computational models and laboratory experiments (reviewed by Stüeken et al. 2016a). By some estimates, these fluxes could have approached the modern biological $\mathrm{N}_{2}$ fixation rate and may thus have been sufficient for driving the early biosphere and for modulating atmospheric $\mathrm{N}_{2}$ pressures over long periods of time. However, the estimated global fluxes are necessarily based on parameters that are very poorly constrained, such as the rate of lightning, hydrothermal circulation, or oxidative volcanism on the early Earth. It is therefore equally likely that abiotic $\mathrm{N}_{2}$ fixation flux was insufficient to sustain a significant biosphere, which would have favored an early origin of the nitrogenase enzyme.

\subsection{The Emergence of Nitrogenase and Aerobic Nitrogen Metabolisms}

Early phylogenetic reconstructions placed the origin of biological $\mathrm{N}_{2}$ fixation into the Paleoproterozoic, around $2 \mathrm{Ga}$ (Boyd et al. 2011). This conclusion was supported by the observation that most nitrogenases strictly require molybdenum as a catalyst (McGlynn et al. 2012), because geochemical data suggest that molybdenum was scarce in seawater until after the Paleoproterozoic Great Oxidation Event ( 2.3 Ga, Anbar 2008; Scott et al. 2008). However, more recent phylogenetic analyses point to a much earlier origin of nitrogenase, possibly going back as far as the last universal common ancestor (LUCA), which probably lived in the Hadean or early Archean (Weiss et al. 2016). This inference can be reconciled with the strict requirement for molybdenum if hydrothermal source fluxes are taken into account. Off-axis hydrothermal vents contribute around $13 \%$ of the modern marine molybdenum budget (Wheat et al. 2002), and data from a hydrothermally altered Archean seafloor (Sulphur Springs Group, 3.3 Ga) show that hydrothermal fluids actively leached molybdenum from volcanic rocks at that time (Huston et al. 2001). Furthermore, culturing studies have demonstrated that biological $\mathrm{N}_{2}$ fixation can be maintained down to around $5 \mathrm{nM}$ of molybdenum (Zerkle et al. 2006; Glass et al. 2010), which is within the estimated range for 
the early ocean (1-10 nM; Reinhard et al. 2013). It is therefore likely that molybdenum was available in sufficient quantities, especially in the vicinity of hydrothermal settings. Importantly, the nitrogenase enzyme also contains an iron-sulfur cluster as well as the only known carbide atom in modern biology (Preiner et al. 2019). Both iron-sulfur clusters and carbides are produced in hydrothermal environments, which may indicate that this enzyme originated in a hydrothermal environment, possibly by modification of a geochemical process. In support of this model, biological $\mathrm{N}_{2}$ fixation has been documented from thermophilic methanogenic Archaea that are deeply rooted in the tree of life (Mehta and Baross 2006). Enzymatic $\mathrm{N}_{2}$ and $\mathrm{CO}_{2}$ fixation may thus have originated in similar environmental settings early in Earth's history.

The oldest geochemical evidence of biological $\mathrm{N}_{2}$ fixation in the form of nitrogen isotope ratios goes back to $3.2 \mathrm{Ga}$ (Stuieken et al. 2015). The nitrogenase enzyme only imparts a small isotopic fractionation during the conversion of $\mathrm{N}_{2}$ to $\mathrm{NH}_{4}^{+}$such that sedimentary ${ }^{15} \mathrm{~N} /{ }^{14} \mathrm{~N}$ ratios close to that of atmospheric $\mathrm{N}_{2}$ are indirect evidence for burial of biomass that depended on this metabolism. Abiotic processes such as lightning and photochemical reactions seem to impart large negative fractionations (Kuga et al. 2014; Moore 1977) that are inconsistent with this record. Well-preserved sedimentary rocks throughout the Mesoand Neoarchean preserve signatures of biological $\mathrm{N}_{2}$ fixation in a range of environmental settings (Stüeken et al. 2015; Stüeken and Buick 2018; Koehler et al. 2019; Ossa Ossa et al. 2019). Such geochemical records preserved in bulk rocks are unlikely to capture rare metabolisms that are only expressed by a small fraction of the ecosystem. Hence these data collectively indicate that a large proportion of the Archean biosphere had become independent from abiotic sources of fixed nitrogen. The drawdown of atmospheric $\mathrm{N}_{2}$ (Som et al. 2016) would therefore have been dependent on biological productivity and biomass burial, which was in turn perhaps limited by low supplies of phosphorus (Kipp and Stüeken 2017; Reinhard et al. 2017).

The magnitude of the nitrogen flux from the atmosphere into geological archives via biomass burial also depends on the efficiency of remineralization, which ultimately returns nitrogen back to the atmosphere. Ferric iron can convert ammonium to $\mathrm{N}_{2}$ (Yang et al. 2012), but in the Archean this metabolism would have been restricted to shelf environments where ferric iron may have been produced by photoferrotrophs (Crowe et al. 2008). Conversion of ammonium to nitrate (i.e. nitrification) above $\mathrm{pH} 6.5$ requires $\mathrm{O}_{2}$ (Stüeken et al. 2016a). Hence the efficient production of nitrate (which can subsequently be reduced to $\mathrm{N}_{2}$ by denitrifying organisms) would have required the emergence of oxygenic photosynthesis. Isotopic evidence of at least locally aerobic biological nitrogen cycling dates back to around 2.66 Ga (Godfrey and Falkowski 2009; Koehler et al. 2018) and possibly earlier (Delarue et al. 2018; Homann et al. 2018). It has been proposed that the rise of coupled nitrificationdenitrification would have induced a nitrogen crisis, because it leads to a net nitrogen loss from the ocean (Fennel et al. 2005). However, increasing supplies of molybdenum with the onset of oxidative weathering (Stüeken et al. 2012) would probably also have allowed for higher rates of biological $\mathrm{N}_{2}$ fixation to offset the loss of fixed nitrogen from the water column.

Regarding atmospheric evolution, the rise of nitrification-denitrification would probably not have had a significant effect on net nitrogen burial in marine sediments, because, as noted above, the nitrogen burial flux is primarily controlled by biomass burial. The Archean ocean prior to the onset of nitrification was probably ammonium-poor, prohibiting efficient abiotic nitrogen burial through adsorption on clay minerals (Stiieken 2016). Biological $\mathrm{N}_{2}$ fixation is an energetically costly process, and hence organisms are unlikely to have built up an excess reservoir of ammonium in Archean seawater. However, the expansion of ammonium oxidation around the GOE would probably have accelerated the rate of oxidative 
ammonium weathering on land (Stüeken et al. 2016b), which constitutes a significant flux of nitrogen today (Houlton et al. 2018). Nitrification-denitrification of this continental ammonium reservoir may have contributed to increasing atmospheric $\mathrm{N}_{2}$ levels at that time (Stuieken et al. 2016b). It is therefore conceivable that Earth's biosphere has had a significant impact on not just atmospheric composition but also on total air pressure over geologic timescales (Som et al. 2016).

\section{Stellar Evolution and Atmospheric Erosion}

In addition to the geological and biological processes discussed above, the evolution of solar radiative properties would have had a significant effect on the evolution of Earth's atmosphere. While the evolution of the solar bolometric luminosity over time is well known (e.g. Sackmann and Boothroyd 2002), the solar XUV evolution and the magnetic activity of the Sun are less well understood. By the time the Sun had developed into a main sequence star, its bolometric luminosity was only about $70 \%$ of the present-day value but increased over time whereas the magnetic and XUV activity (i.e. the x-ray and EUV flux activity) steadily declined from the beginning to the present-day (e.g. Ribas et al. 2005; Guedel 2007; Füri et al. 2020, this issue). Recent studies of the magnetic and XUV evolution of solar-like stars (Johnstone et al. 2015a,b; Tu et al. 2015) found that these are strongly linked to the star's rotational evolution. As the rotation slows down, the XUV flux and the mass loss of a star also decline. After about a billion years, all stars converge towards one rotational track, but their initial rotational speeds can be very different, with the fastest rotators having the highest XUV fluxes and stellar mass losses and the slowest rotators the lowest, respectively (Johnstone et al. 2015a,b; Tu et al. 2015). For example, during the late Hadean eon, the XUV flux from a slow rotating Sun would have been about 15 times the present-day value, whereas for a fast rotating Sun it would have been up to 150 times as high as of today. Even though it is not yet entirely known whether the Sun was a slow, moderate or fast rotator, the latter seems unlikely (e.g. Lammer et al. 2020). Understanding the Sun's rotational evolution is crucial for reconstructing the evolution of the terrestrial atmosphere since higher XUV fluxes can have profound effects on atmospheric escape. In addition, atmospheres of different compositions respond very differently to an increase in solar XUV.

Several studies (Tian et al. 2008a,b; Johnstone et al. 2018) have shown that a nitrogendominated atmosphere (with a present-day $\mathrm{N}_{2}-\mathrm{CO}_{2}$ mixing ratio) adiabatically expands when the solar XUV flux exceeds a certain threshold (see Fig. 2), which is typically around 5-6 times the present-day value. This effect is accompanied by fast atmospheric bulk flow velocities that start to approach the escape velocity for values around 10 times the presentday XUV flux. At that point, the atmosphere transitions into hydrodynamic escape. Under such high XUV fluxes the exobase of a nitrogen-dominated atmosphere extends several Earth radii above the surface, thus reaching above the magnetopause standoff-distance (Lichtenegger et al. 2010). In addition to the strong thermal losses (Tian et al. 2008a,b), such an atmosphere would be strongly susceptible to non-thermal escape processes like ion pick-up (Lichtenegger et al. 2010; Lammer et al. 2018), facilitated by a much stronger early solar wind (Johnstone et al. 2015a). In fact, even without thermal escape, such a nitrogendominated atmosphere would have been lost within a few million years (Lichtenegger et al. 2010). A more recent study (Johnstone et al. 2019) has additionally shown that such atmospheres would also quickly be lost thermally around active G-type stars comparable to the young Sun during the Hadean and early Archean eons. A nitrogen-dominated atmosphere was thus unlikely to survive the early stages of the solar system. However, there is no sign 


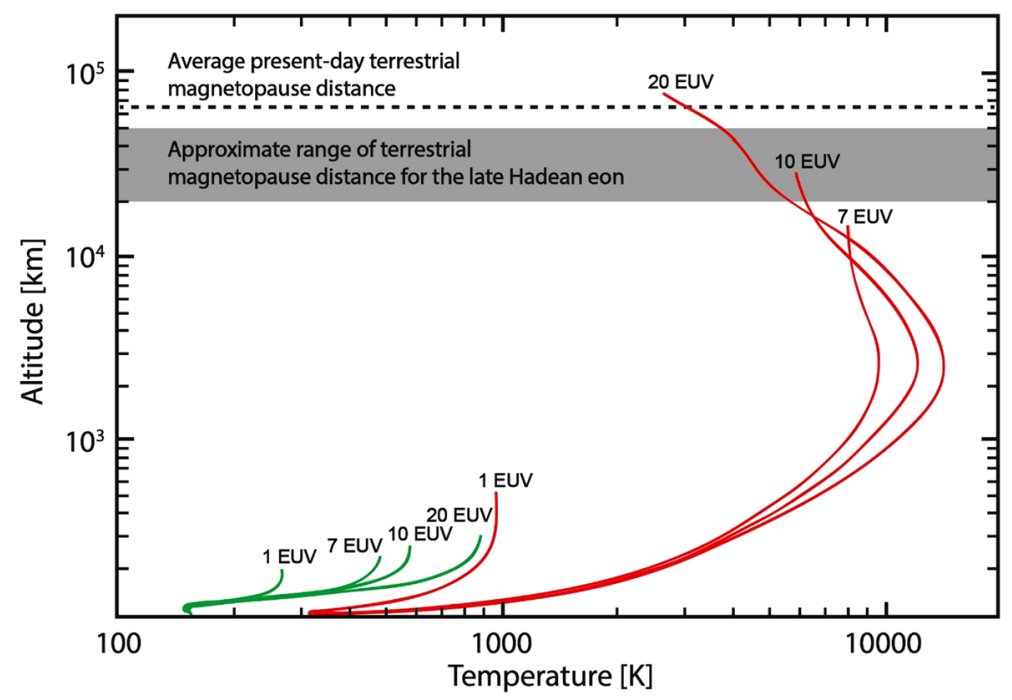

Fig. 2 Different thermospheric temperature profiles and corresponding exobase levels for 1, 7, 10 and 20 times the present-day XUV flux for a nitrogen-dominated atmosphere in red (as for the present-day Earth) (Tian et al. 2008a) and for a Venus-like atmosphere in green with $96 \% \mathrm{CO}_{2}$ (Kulikov et al. 2006). Due to the efficient infrared-cooling of $\mathrm{CO}_{2}$ in the thermosphere of Venus exobase temperatures and levels are significantly lower than for the nitrogen-dominated atmosphere. The grey shaded area represents potential ranges for the terrestrial paleo-magnetosphere at the late Hadean eon (Scherf et al. 2018). Figure adopted from Lammer et al. (2008)

of such escape in the terrestrial ${ }^{14} \mathrm{~N} /{ }^{15} \mathrm{~N}$ isotopic record. The lighter isotope should have escaped more easily than the heavier one if a strong atmospheric escape took place in the past (Cartigny and Marty 2013; Füri and Marty 2015; Avice and Marty 2020, this issue). The small ${ }^{14} \mathrm{~N} /{ }^{15} \mathrm{~N}$-disequilibrium between the atmosphere and the terrestrial mantle compared to, for example, Mars indicates that only a very small fraction of nitrogen escaped over the history of the Earth (Lammer et al. 2018), and this escape process likely ended before $3.5 \mathrm{Ga}$, as isotopic data show nearly constant values since that time (Marty et al. 2013; Avice et al. 2018). So what happened to the atmosphere? A solution might be the following.

As briefly mentioned in Sect. 3, atmospheres with different compositions respond very differently to high XUV fluxes. A higher atmospheric partial pressure of $\mathrm{CO}_{2}$, for instance, can prevent the exobase from expanding dramatically (Fig. 2), because $\mathrm{CO}_{2}$ serves as an infrared cooler in the upper atmosphere (Kulikov et al. 2007; Lammer et al. 2008; Johnstone et al. 2018).

The $\mathrm{N}_{2}-\mathrm{CO}_{2}$-mixing ratio might therefore be crucial for the survival of the early terrestrial atmosphere. It has indeed long been suggested that the $\mathrm{CO}_{2}$ partial pressure during the Hadean and early Archean was significantly higher than today (e.g. Holland 1984; Berner and Kothavala 2001; Dauphas and Kasting 2011; Reinhard and Planavsky 2011; Goldblatt and Zahnle 2011) with values of up to about 100-1000 times the Present Atmospheric Level (PAL) (Hessler et al. 2004). A more recent study (Kanzaki and Murakami 2015) has even shown that around 2.7 billion years ago the $\mathrm{CO}_{2}$ partial pressure in the atmosphere was as high as 80-100 PAL. These numbers make it plausible that high $\mathrm{CO}_{2}$ levels limited $\mathrm{N}_{2}$ escape by the mechanism described above. It is, however, not yet entirely clear which mixing ratios could have prevented an atmosphere with a significant of $\mathrm{N}_{2}$ from escaping to space. A 
later build-up of the Earth's nitrogen-dominated atmosphere might be an alternative solution to this paradox (Lammer et al. 2018, 2019).

There is one geological marker that indicates significant atmospheric loss of hydrogen from the terrestrial atmosphere: the fractionation of the heavy Xe-isotopes (e.g. Srinivasan 1976; Zahnle et al. 1990; Pepin 2000; Pujol et al. 2009, 2011; Avice et al. 2018; Zahnle et al. 2019; Avice and Marty 2020, this issue). The underlying fractionation process is expected to be mass-dependent dragging of $\mathrm{Xe}^{+}$by hydrodynamically escaping $\mathrm{H}^{+}$due to a strong repulsive Coulomb interaction between these ions, which preferentially happens via the polar cusps (Zahnle et al. 2019). Since Xe is easily ionized compared to other elements including hydrogen, this process can lead to strong $\mathrm{Xe}^{+}$escape rates while the escape of lighter species such as $\mathrm{N}$ and other noble gases (Ne, Ar, Kr, Avice et al. 2018) is not significant. For this process to be efficient, however, high XUV fluxes, probably $>10$ times the present-day value, and a significant hydrogen mixing ratio in the upper atmosphere might be needed (Zahnle et al. 2019). It is, however, not entirely clear how the atmospheric composition influences the escape of Xe; Zahnle et al. (2019) did not include atmospheric $\mathrm{N}_{2}$ into their model, whose total pressure might influence the escape process of the heavy $\mathrm{Xe}^{+}$.

Fractionation of $\mathrm{Xe}$ isotopes appears to have ended towards the end of the Archean $(\mathrm{Pu}-$ jol et al. 2011), which indicates a complex interplay of solar XUV flux, escape of hydrogen, atmospheric composition and the terrestrial magnetic field. Understanding the "missing Xenon" paradox (Ozima and Podosek 1983) — in particular together with the small terrestrial ${ }^{14} \mathrm{~N} /{ }^{15} \mathrm{~N}$-disequilibrium-is therefore a crucial component for the reproduction of not only the terrestrial atmospheric evolution but also of the XUV flux evolution and potential bursts and flares of the young Sun.

\section{Evidence and Mechanisms of Photochemistry in Earth's Anoxic Atmosphere}

Clues to paleo-environmental conditions are left behind in Earth's sedimentary rock record. The ancient sediments that have somehow survived the gauntlet of tectonic recycling can be investigated for traces they record about the oceanic environment they were deposited in. Various proxies have been developed to constrain the temperature and chemistry of the originating waters, along with quantifying the disequilibrium imparted by the metabolisms of ancient life (Sect. 4). Unfortunately, Earth's sedimentary record is effectively absent for the first billion years of Earth's history and somewhat sparse during the second billion. As a result, the paleo-environments that we have to interrogate do not constrain Earth's tumultuous early days but are limited to post- accretion/heavy bombardment/blow-off conditions known as the "secondary atmosphere" (see Sects. 2-5). This term refers to what most Earth Scientists consider as simply the atmosphere-the envelope of gas derived primarily from volcanic outgassing subject to intense biological meddling. Photochemistry-the interaction of solar light and absorption/scattering/transformation of input gases-sets the bulk composition of the atmosphere and the UV environment at the surface, both of which play strong roles in climate and planetary habitability. Understanding the bulk composition of the atmosphere from ancient ocean sediments is a frontier interdisciplinary challenge.

As atmospheric gases are generally not preserved directly by the rock record, various geochemical measurements have been proposed as proxy for atmospheric information. Proxies are developed from studying modern analog processes that generally involve quantitative involvement of atmospheric gases, but most of these processes are indirect (e.g., via chemical weathering) and can suffer from non-uniqueness (e.g., oxidation can occur in the water 
column or sediments without being atmospheric). The only direct proxies for atmospheric chemistry that exist are mass-independent isotope fractionations, or MIF, which originate primarily in gas-phase photochemical reactions (Thiemens 2006). MIF signals are known to arise in ozone formation (Thiemens et al. 2012), and via various photochemical reactions involving sulfur (Ono 2017) and mercury (Blum et al. 2014). MIF has additional strength as atmospheric proxy given that these anomalous isotopic signals persist through most of the transformations that occur during biogeochemical cycling prior to deposition into the sediments. These atmospheric signatures are therefore relatively easy to transfer and store in the permanent rock record, where they will remain unless subjected to significant metamorphic temperatures. While MIF in $\mathrm{O}, \mathrm{S}$, and $\mathrm{Hg}$ have many interesting roles in modern and paleoclimates, this section will focus on reviewing MIF-S, which has the most data relevant to the first two billion years of Earth history.

\subsection{Discovery and Expansion of the MIF-S Dataset}

Sulfur exists in multiple redox states in atmospheric and marine environments but is preserved in the rock record in two distinct forms - sulfide and sulfate. MIF-S (quantified simply as $\Delta^{33} S=\delta^{33} S-0.52 \delta^{34} S$ and $\Delta^{36} S=\delta^{36} S-1.9 \delta^{34} S$ ) measurements of opposing magnitudes were discovered in both sulfides and sulfates in the year 2000. In the subsequent 19 years, the global database of MIF-S measurements has grown substantially revealing both temporal and stratigraphic variations, with substantial reviews in 2011 (Johnston 2011) and 2017 (Ono 2017) (see also Fig. 3). Like nearly every other geochemical measurement, the ability to measure the signal has to date outpaced our ability to interpret it. The most profound interpretation that has been derived from MIF-S is that the atmosphere prior to about 2.3 billion years ago was devoid of oxygen gas, which effectively resolved a century-old debate. Critically, this interpretation requires only the mere presence of MIF-S. As the data also show substantial variations in magnitude, sign, facies, and derived slopes, there is significant hope that additional constraints about the specific gases in the reducing atmosphere can to be determined from this record.

\subsection{Interpreting Sulfur MIF}

The primary interpretation of a reducing atmosphere stemmed from three foundational papers which combined data, experiments, and theory and collectively demonstrated that MIF$\mathrm{S}$ could not be exported from atmospheres with more than $1 \mathrm{ppm}$ of $\mathrm{O}_{2}$. Farquhar et al. (2000) presented the first data and hypothesized a role for reducing atmospheric chemistry. Follow-on experiments irradiated $\mathrm{SO}_{2}$ gas and quantified MIF-S signals in the elemental sulfur and residual $\mathrm{SO}_{2}$ (Farquhar et al. 2001). The magnitudes, signs, and $\Delta^{36} \mathrm{~S} / \Delta^{33} \mathrm{~S}$ slope of the measured signal changed with wavelength of light and were best explained by $\mathrm{SO}_{2}$ photolysis in the absence of $\mathrm{O}_{2}$. Pavlov and Kasting (2002) used a 1-D photochemical model and showed that MIF-S propagates through all atmospheric S species, highlighted the role that multiple exit channels play in signal preservation, and demonstrated that atmospheres with more than $1 \mathrm{ppm} p_{\mathrm{O}_{2}}$ will turn all input sulfur to sulfate, so that MIF-S preservation should only occur in reducing atmospheres. The most substantial challenge to the interpretation was raised by Ohmoto et al. (2006) who argued that the low magnitudes of $\Delta^{33} \mathrm{~S}$ seen between 3.2-2.7 Ga might reflect mass conservation effects in an oxic atmosphere. However, Farquhar et al. (2007) demonstrated using $\Delta^{36} \mathrm{~S} / \Delta^{33} \mathrm{~S}$ slopes that these signals unequivocally preserve MIF-S, even though the magnitudes are low. 


\subsubsection{Modern Updates to the Initial Interpretation}

Follow-on work has confirmed the primary interpretation of a reducing early atmosphere, although the specific mechanism and theory behind it have changed, and are still undergoing revision (Ono 2017; Sect. 7) Atmospheric exit channels remain a key part of the story, but the mechanism is no longer thought to be solely $\mathrm{SO}_{2}$ photolysis. While a single dominant source mechanism can produce variable magnitudes of MIF-S depending on the exit channels (Claire et al. 2014), subsequent processing in the oceans would likely reduce magnitudes of signatures that are preserved in various facies (Halevy 2013). A current consensus view is that multiple mechanisms involving sulfur photochemistry may be integrated into the rock record. This is also true of the experimental work done to constrain the relevant fractionation factors.

\section{3 $\mathrm{SO}_{2}$ Photolysis Experiments}

Experiments following on from Farquhar et al. (2001), revealed that $\mathrm{SO}_{2}$ photolysis with broadband lamps displayed varying sulfur MIF magnitudes with $\mathrm{SO}_{2}$ and total pressure (Masterson et al. 2011; Whitehill and Ono 2012; Endo et al. 2016). Interpretation of experimental results to the natural atmosphere are complicated by self-shielding conditions in the chamber experiments, and multiple important gas mixtures remain to be tested under atmospherically relevant conditions. Hints towards understanding the mechanism were provided by measurements of $\mathrm{SO}_{2}$ absorption cross-section (Danielache et al. 2008; Endo et al. 2015), although these measurements did not resolve the potential effect of hyper-fine structure (Stark et al. 1999; Lyons 2009). Recent work has untangled the role of background pressure from self-shielding (Endo et al. 2019), and implies that pressure broadening in the terrestrial atmosphere may remove the need to consider the $\mathrm{SO}_{2}$ fine-structure. Overall, $\mathrm{SO}_{2}$ photolysis has been unequivocally shown to produce MIF-S, but the magnitude of $\Delta^{33} S$ produced in low pressure atmospheres appears to be smaller than the observed data, and a consensus viewpoint is that another mechanism in addition to $\mathrm{SO}_{2}$ photolysis is contributing to the observed signal.

\subsubsection{Other Mechanisms Known to Produce MIF-S}

MIF-S mechanisms have become quite a bit more complicated than the corresponding case of MIF-O, for which only one atmospheric mechanism has been revealed in 40 years of study. MIF-S has been demonstrated to arise from $\mathrm{CS}_{2}$ photolysis (Zmolek et al. 1999), and $\mathrm{SO}_{2}$ photodeexcitation (Whitehill and Ono 2012). Theory supports MIF-S formation in $\mathrm{SO}_{2}$ photoexcitation (Danielache et al. 2012), SO photolysis (Danielache et al. 2014) and in the polymerization of elemental sulfur (Babikov 2017; Harman et al. 2018b). There are a number of complications involved with extrapolating from experimental and theoretical results to natural atmospheric conditions, as multiple mechanisms are likely to be involved during and experiment. Extrapolation of fractionation factors to natural atmospheric conditions also remains challenging. Recently theorized effects in sulfur polymerization can create large magnitude MIF-S signals but need experimental verification.

\subsection{What Is Needed to Move Forward?}

It is clear that the extensive MIF-S dataset contains far more information than a single on/off switch for $\mathrm{O}_{2}$ (Ono 2017). There are changes in the sulfur MIF record between the Paleo-, 
Meso-, and Neo-Archean that are best described as changes in the transparency to UV driven by varying gas compositions at these times. In addition, stratigraphic changes in MIF-S hint at time-dependent shifts in atmospheric chemistry on shorter timescales (Zerkle et al. 2012; Izon et al. 2015, 2017). Quantitative constraints on the composition of reducing atmosphere appears feasible given the quality of the observed record, but all hinges on identifying and quantifying all of the anomalous fractionation factors which emerge from sulfur gas phase chemistry. It is not clear that this has occurred yet-it may have, but there certainly exists the possibility that one or more major processes have yet to be uncovered.

Once all fractionation factors are identified and quantified, a number of challenges remain. This include a full calibration and validation of the modern sulfur MIF record generated by stratospheric volcanic eruptions as recorded in ice cores (Savarino et al. 2003). Recent methodological advances have enabled sampling of $\Delta^{33} S$ at $\sim$ monthly resolution (Burke et al. 2019) providing a robust dataset for exploration with a time-dependent photochemical plume model, although detection of $\Delta^{36} \mathrm{~S}$ at small sample size remains a frontier challenge. Once calibrated against the modern (and all experimental work), photochemical modelling could be undertaken with a full Monte-Carlo exploration over the unknown Archean parameter space, with the goal of identifying which background atmospheres reproduce, for example, the Neoarchean reference array of $\delta^{34} S / \Delta^{33} S \sim 1$ and $\Delta^{36} S / \Delta^{33} S \sim-0.9$. Monte-Carlo uncertainty propagation coupled to sensitivity analysis could be used to identify, measure, and thus reduce uncertainty in any reactions, crosssections, or other internal model parameterizations which contribute significant uncertainty to MIF-S prediction (Hébrard et al. 2009). An ultimate goal would be an inverse modelone in which the data itself are allowed to constrain a Monte-Carlo parameter search-which could identify not only the portions of unknown parameter space which can match the data, but also constrain their likelihood. In summary, interpretation of atmospheric composition from sulfur MIF measurements and experiments remains a challenging frontier but is ultimately a surmountable problem.

\section{Global Methanotrophy and the Possibility of a Neoarchean CO-World}

\subsection{The Negative $\delta^{13} \mathrm{C}_{\text {org }}$ Anomaly in the Late Archean: "Global Methanotrophy"?}

Stable isotopes of sedimentary rocks reflect biogeochemical cycling and its evolution through time (Fig. 3). Since the pioneering works of the Precambrian Palaeontology Research Group (Schidlowski et al. 1983; Hayes 1983), it has been known that carbon isotopes of sedimentary carbonate $\left(\delta^{13} \mathrm{C}_{\text {carb }}\right)$ and organic matter $\left(\delta^{13} \mathrm{C}_{\mathrm{org}}\right)$ show an isotopic difference of about $25 \%$ on average since at least 3.5 billion years ago $(\mathrm{Ga})$. This observed isotopic fractionation is primarily derived from biological $\mathrm{CO}_{2}$ fixation: autotrophic organisms preferentially convert ${ }^{12} \mathrm{C}$ from mantle-derived $\mathrm{CO}_{2}(\sim-5 \%)$ into organic carbon $(-25 \%)$, pushing the remaining inorganic carbon, which is deposited as carbonate, to heavier values $(\sim 0 \%$ ) relative to the starting composition.

This simplest explanation may not be applicable for the late Archean record from 2.7 to $2.5 \mathrm{Ga}$, when the organic carbon exhibit large ${ }^{13} \mathrm{C}$-depletion below $-40 \%$ (Fig. 1). Apart from localized occurrences, such a large depletion over extended temporal and spatial scales is not observed outside of the late Archean time window, suggesting a distinct biogeochemical carbon cycling during in the period. A leading interpretation of these data is the "global methanotrophy" hypothesis" (Hayes 1994). 

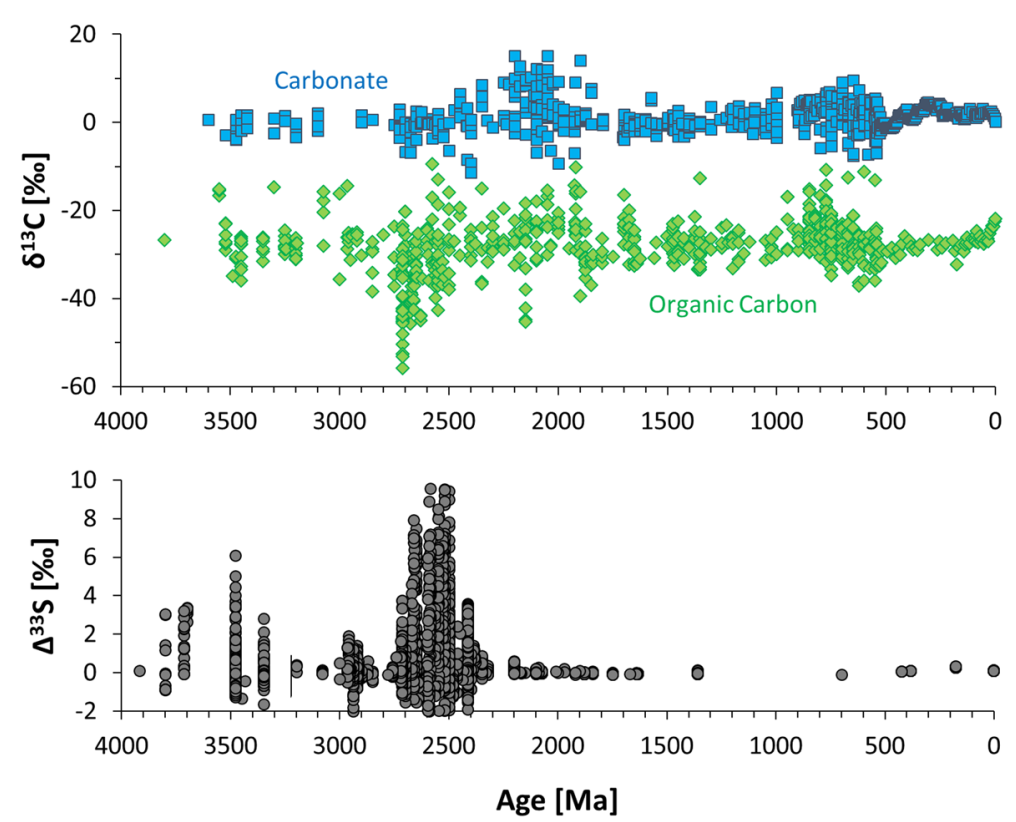

Fig. 3 Stable carbon and sulfur isotopes through time. In the upper panel, blue and orange symbols show carbonate carbon $\left(\delta^{13} \mathrm{C}_{\mathrm{org}}\right)$ and organic carbon $\left(\delta^{13} \mathrm{C}_{\mathrm{carb}}\right)$ isotopes in sedimentary rocks, respectively. Lower panel shows Sulfur Mass Independent Fractionation $\left(\Delta^{33} S\right)$ of sedimentary sulfide and sulfate measured by bulk rock chemical extraction methods. In the late Archean from 2.7 to $2.5 \mathrm{Ga}$, both the $\delta^{3} \mathrm{C}_{\text {org }}$ and $\Delta^{33} \mathrm{~S}$ values show larger variation including negative $\delta^{13} \mathrm{C}$ below $-40 \%$

The highly negative $\delta^{13} \mathrm{C}_{\text {org }}$ are unlikely to have been produced solely by photosynthesis and other autotrophic carbon fixation pathways, which exhibits fractionations less than $40 \%$ against $\mathrm{CO}_{2}$ (e.g., House et al. 2003). Instead, these values are consistent with methanotrophic metabolisms in which isotopically-light $\mathrm{CH}_{4}$ is incorporated into biomass, leading to $\delta^{13} \mathrm{C}_{\text {org }}$ well below $-40 \%$. These observations are what led Hayes (1994) to propose the "global methanotrophy hypothesis" where methanotrophic organisms appeared at around $2.7 \mathrm{Ga}$ and started to incorporate atmospheric $\mathrm{CH}_{4}$ globally in the late Archean. Atmospheric model calculations indicate that Archean $\mathrm{CH}_{4}$ levels were likely high in the anoxic Archean atmosphere (Pavlov et al. 2001). Importantly, microbial production of $\mathrm{CH}_{4}$ (methanogenesis) dates back to at least $3.5 \mathrm{Ga}$ (Ueno et al. 2006). Global methanotrophy may have been terminated by increasing atmospheric oxygen levels, which removed $\mathrm{CH}_{4}$ from the atmosphere, and thus the negative $\delta^{13} \mathrm{C}_{\text {org }}$ signature disappeared after about $2.4 \mathrm{Ga}$. The onset of the global methanotrophy episode is more difficult to explain, but it could potentially be related to localized appearances of oxygenic photosynthesis at around $2.7 \mathrm{Ga}$ (Eigenbrode and Freeman 2006; Stüeken et al. 2017). Aerobic methanotrophs not only assimilate $\mathrm{CH}_{4}$ but also couple the oxidation of $\mathrm{CH}_{4}$ to $\mathrm{O}_{2}$ for energy. Anaerobic methanotrophs, which use nitrate, ferric iron or sulfate as an oxidant instead of $\mathrm{O}_{2}$, would benefit indirectly from increased $\mathrm{O}_{2}$ levels, because $\mathrm{O}_{2}$ generates more of these alternative oxidants through oxidation of ammonium, ferrous iron and sulfide, respectively. Originally, Hayes (1994) explained the expansion of methanotrophy by the concomitant appearance of oxygenic phototrophs based on the occurrence of stromatolites and cyanobacterial microfossils at about 2.7 Ga (Packer 1990). However, it remains conceivable that the isotopic anomaly 
was caused by anaerobic methanotrophs that received their oxidants without the need for $\mathrm{O}_{2}$ (Hinrichs 2002).

Irrespective of the exact mechanism, the period of highly negative $\delta^{13} \mathrm{C}_{\text {org }}$ value likely points to a redox transition of in the atmosphere and ocean. It is important to note that not only carbon, but also sedimentary nitrogen and iron isotopes are anomalous during this time period compared to the earlier Archean (Pinti and Hashizume 2010; Koehler et al. 2018), possibly indicating increasing abundances of oceanic nitrate and iron oxide. It is tempting to conclude that a gradual and perhaps localized oxidation of surface environments not only transformed the biogeochemical carbon cycle, but also sulfur, nitrogen, and iron cycling in the time period from 2.7 to $2.5 \mathrm{Ga}$.

\subsection{Sulfur Isotopic Anomalies in the Neoarchean and Its Correlation with the $\delta^{13} \mathrm{C}_{\text {Org }}$}

In contrast to the anomalous $\delta^{13} \mathrm{C}_{\mathrm{org}}, \delta^{15} \mathrm{~N}$ and $\delta^{54} \mathrm{Fe}$, the $\delta^{34} \mathrm{~S}$ record of sedimentary sulfide and sulfate do not show a distinctive signature in the Neoarchean. Instead, the $\Delta^{33} \mathrm{~S}$ value (Sect. 6) shows the largest scatter during this time (Fig. 1). Since large perturbations in MIF-S are thought have been produced in the atmosphere, the apparent correlation between $\Delta^{33} \mathrm{~S}$ and $\delta^{13} \mathrm{C}_{\text {org }}$ may suggest a link between biogeochemical cycles and atmospheric chemistry. So far, the environmental factors controlling the magnitude and preservation of $\Delta^{33} \mathrm{~S}$ values is largely unknown because a clear understanding of the primary photochemical mechanism of S-MIF production and its transfer from the atmosphere to sediments is lacking. Based on experimental studies, large $\Delta^{33} S$ fractionations over $10 \%$ can be produced when the optical thickness of $\mathrm{SO}_{2}$ is large enough (Lyons 2009; Ono et al. 2013; Endo et al. 2016). Such a high optical thickness, i.e. higher atmospheric $p_{\mathrm{SO}_{2}}$, could have been produced by enhanced subaerial volcanism at that time. This suggestion is roughly consistent with the geological record of continental crust formation estimated from age populations of zircons (Condie 2005). However, although the link to "global methanotrophy" remains unclear in this scenario, it is also important to keep in mind that the atmospheric $\Delta^{33} \mathrm{~S}$ signal can be diluted by the addition of mass-dependently fractionated "normal" sulfur sources before preservation in sediment (e.g., sulfate supplied from oxidative weathering of continents, hydrothermal input, or volcanic $\mathrm{H}_{2} \mathrm{~S}$; Halevy 2013). Thus, the magnitude of $\Delta^{33} \mathrm{~S}$ alone cannot be interpreted unambiguously.

An alternative interpretation may be obtained from the analysis of both $\Delta^{33} \mathrm{~S}$ and $\Delta^{36} \mathrm{~S}$. Like $\Delta^{33} \mathrm{~S}, \Delta^{36} \mathrm{~S}$ is an expression of the photochemically-induced mass independent fractionation that was produced in the Archean atmosphere. Even though the atmospheric signal of both $\Delta^{33} \mathrm{~S}$ and $\Delta^{36} \mathrm{~S}$ can be diluted by the mechanisms listed above, the $\Delta^{36} \mathrm{~S} /$ $\Delta^{33} \mathrm{~S}$ ratio would remain unchanged because the "normal" sulfur sources should exhibit $\Delta^{33} \mathrm{~S}=\Delta^{36} \mathrm{~S}=0$. Interestingly, in the late Archean, the $\Delta^{36} \mathrm{~S} / \Delta^{33} \mathrm{~S}$ ratio shows systematic fluctuations around a mean of -0.9 , and these fluctuations seem to correlate with $\delta^{13} \mathrm{C}_{\mathrm{org}}$ anomalies in multiple depositional basins (Ono et al. 2003; Kaufman et al. 2007; Zerkle et al. 2012; Izon et al. 2015; Mishima et al. 2017). The apparent correlation may possibly imply the connection between the atmosphere and the biosphere through $\mathrm{CH}_{4}$ metabolisms. Based on a photochemical model, Izon et al. (2017) and Claire et al. (2014) argued that the formation and thickness of a hydrocarbon haze in the atmosphere can change the S-MIF signal by altering the transmission spectrum of UV radiation. Changes in the UV wavelength affect $\mathrm{SO}_{2}$ photolysis and thus may control the change in $\Delta^{36} \mathrm{~S} / \Delta^{33} \mathrm{~S}$ ratio. The effect is primarily derived from the difference in absorption cross sections of $\mathrm{SO}_{2}$ isotopologues, although a later experimental study demonstrated that the isotopologue cross-section should 
be refined for predicting $\Delta^{33} \mathrm{~S}$ and $\Delta^{36} \mathrm{~S}$ more precisely with a proper consideration of total pressure and temperature (Endo et al. 2019). Furthermore, laboratory experiments of $\mathrm{SO}_{2}$ photochemistry have demonstrated that the $\Delta^{36} \mathrm{~S} / \Delta^{33} \mathrm{~S}$ ratio is more sensitive to the availability of reducing gas species (potentially $\mathrm{H}_{2}, \mathrm{CH}_{4}$ or $\mathrm{CO}$ ) rather than haze thickness (Whitehill et al. 2013; Endo et al. 2016). Thus, our understanding of the potential link with the atmospheric state and the late Archean $\delta^{13} \mathrm{C}_{\text {org }}$ anomaly is still limited.

\subsection{An Alternative Scenario: A Late Archean CO-World}

Alternative to the "global methanotorophy" scenario, the anomalously low $\delta^{13} \mathrm{C}_{\text {org }}$ in the late Archean may possibly be explained by non-biological processes. Pavlov et al. (2001) pointed out that organic haze produced from $\mathrm{CH}_{4}$ by photochemical reactions in the atmosphere should be highly depleted in ${ }^{13} \mathrm{C}$, and thus the deposition of the haze in surface environments may possibly contribute the observed negative $\delta^{13} \mathrm{C}_{\text {org }}$ anomaly in sediment at that time. However, also in this case, the link between the carbon isotopes and S-MIF remains uncertain.

As noted above, high $p_{\mathrm{SO}_{2}}$ seems to be required to explain the observed large $\Delta^{33} \mathrm{~S}$ over $+10 \%$ due to the significant $\mathrm{SO}_{2}$-self-shielding effect during $\mathrm{SO}_{2}$ photolysis. However, self-shielding alone should produce the S-MIF with a $\Delta^{36} \mathrm{~S} / \Delta^{33} \mathrm{~S}$ ratio of about -2.5 (Lyons 2009; Ono et al. 2013; Endo et al. 2016), which does not match the late Archean record $\left(\Delta^{36} \mathrm{~S} / \Delta^{33} \mathrm{~S}\right.$ ranges from -1.52 to -0.85$)$. To resolve this issue, Endo et al. (2016) demonstrated experimentally that the shallower $\Delta^{36} \mathrm{~S} / \Delta^{33} \mathrm{~S}$ slope about -1 can be produced when the photoproduct $\mathrm{SO}$ comes not only from $\mathrm{SO}_{2}$ photolysis (destruction of the molecules, 185-220 nm) but also from the $\mathrm{SO}_{2}$ photoexcitation channel (excitation of an electron to a higher energy level, 250-320 nm). The contribution from the $\mathrm{SO}_{2}$ photoexcitation channel is expected in a reducing atmosphere, especially in the presence of carbon monoxide (CO roughly $0.01 \sim 0.1$ bar: Endo et al. 2016). The observed $\Delta^{36} \mathrm{~S} / \Delta^{33} \mathrm{~S}$ ratio around -1 may thus be evidence that the Neoarchean atmosphere was not only rich in $\mathrm{CH}_{4}$ but also $\mathrm{CO}$. A plausible source of $\mathrm{CO}$ would have been photochemical $\mathrm{CO}_{2}$ reduction coupled to the presence of a strong reducing agents (most likely volcanic $\mathrm{H}_{2}$ ) that was supplied directly to the atmosphere (Kharecha et al. 2005; Yung and DeMore 1982).

In such a hypothetical CO-rich atmosphere, low- ${ }^{13} \mathrm{C}$ organic carbon in the form of haze particles may have rained out into surface environments. Based on theoretical calculation of absorption spectra of the $\mathrm{CO}_{2}$ isotopologues (Schmidt et al. 2013), solar UV photolysis of $\mathrm{CO}_{2}$ may cause significant carbon isotopic fractionation of about $200 \%$ because ${ }^{13} \mathrm{C}$ and ${ }^{12} \mathrm{C}$ have quite distinct UV absorption properties. Since the most probable source of atmospheric $\mathrm{CO}$ is from the photodissociation of $\mathrm{CO}_{2}$, the atmospheric $\mathrm{CO}$ would have been highly depleted in ${ }^{13} \mathrm{C}$. Furthermore, the atmospheric $\mathrm{CO}$ could have been converted mainly into formaldehyde and deposited on the surface (Bar-Nun and Hartman 1978; Pinto et al. 1980; Bar-Nun and Chang 1983), where it could have been assimilated into the biosphere.

Although the large isotope effect has not yet been tested quantitatively by laboratory experiment, and the chemical/biological processes to transfer the isotopically depleted $\mathrm{CO}$ into sediment are largely uncertain, the alternative $\mathrm{CO}$-world hypothesis may explain both carbon and sulfur isotope anomalies in the late Archean, and it should be considered as a possible scenario on other exoplanetary worlds. 


\section{Atmospheric Biosignatures on the Early Earth}

Using the early Earth as an analogue for exoplanets not only provides insights into the mechanisms that drive planetary habitability and evolution, but it also allows us to develop methods of detecting microbial biospheres remotely. Remote detection relies on absorption features of diagnostic gases in reflectance spectra of planets. Such diagnostic gases are those that are those that have an overwhelmingly biological source. These signatures are thus dependent on biological metabolisms but also require the characterization of potential abiotic sources that could create 'false positives'.

\subsection{Methane and Other Metabolic Products}

When considering the atmospheric biosignatures on the early Earth we first note that while life likely produces thousands of molecules in small quantities (see Seager et al. 2016), only a few have fluxes high enough to contribute substantially to the atmosphere. Even fewer would be detectable from the perspective of an exoplanet that is similar to early Earth (Rugheimer and Kaltenegger 2018). While it is possible that alternative biochemistries exist, to date we only know of life that uses a carbon-based biochemistry and liquid water. Since carbon dioxide and water are abundant in the Universe (Fortney 2012), it is conceivable that at least some life forms elsewhere evolved using similar chemical energy pathways and would thus potentially be detectable by methods developed based on Earth's biosphere.

While the first life form on Earth is not known, it is postulated that chemoheterotrophic organisms with metabolisms such as iron reduction and methanogenesis arose first due to the relative simplicity of their metabolic pathways. Methane is a gas with both biological and geological sources (Sects. 4, 7). On Earth, however, the biological flux is much higher than the abiotic flux, which is primarily focused around hydrothermal vents and subduction zones (Guzmán-Marmolejo et al. 2013). Given the antiquity of methanogens, the abundance of metabolic substrates for them $\left(\mathrm{CO}_{2}, \mathrm{H}_{2}\right.$ and metal catalysts) and the absence of free oxygen - a major sink for methane-in the Archean, it is thought that atmospheric methane was a large component of Earth's early atmosphere (Claire et al. 2006; Zahnle et al. 2006). Estimates suggest that the residence time of methane would be 100 times greater than it is today. However, as noted above, methane is not unique to biology and 'false positives' could arise on planets around starts with a relatively low UV flux, which may allow abiotic methane to accumulate in the planet's atmosphere (Guzmán-Marmolejo et al. 2013; Domagal-Goldman et al. 2014; Rugheimer et al. 2015a, 2015b).

The Archean Earth may have experienced an episode where methane accumulation was so strong that a hydrocarbon haze formed in the atmosphere (Zerkle et al. 2012). Such a haze creates an additional biosignature, because it would indicate large amounts of methane production and a biosphere dominated by methanogenesis (Arney et al. 2016, 2018). Furthermore, a haze could protect surface environments on the planet from harmful UV-C radiation, which may result in an expansion of the biosphere and thus create a positive feedback on the production of biogenic gases, including hydrocarbons (Arney et al. 2017; Rugheimer et al. 2015b; Hörst et al. 2018; Ozaki et al. 2017). A haze-dominated planet would have detectable spectral features in the UV which could serve as a biosignature of an anoxic world (Arney et al. 2018).

Besides methane, biogenic sulfur gases have been proposed as a biosignature in reducing atmospheres (Domagal-Goldman et al. 2011), although their detection is challenging due to spectral overlap. Phosphine is another gas which has recently been proposed as a biosignature on an anoxic world (Sousa-Silva et al. 2019). Phosphine is produced by some anaerobic 
organisms on Earth (Bains et al. 2019), and it is the simplest, isolated gas without known false positives at detectable levels. Importantly, it has strong spectral features distinct from other biosignatures which if present, could indicate an anoxic biosphere on an extrasolar planet, although its fluxes on modern (and early) Earth are not well understood.

On the modern Earth, $\mathrm{O}_{2}$ is the most notable biosignature gas, produced by oxygenic photosynthesis. However, models have identified many abiotic mechanisms that build up appreciable quantities of this gas and create a false positive. Several of those mechanisms would be present on a young planet (e.g. Hu et al. 2012; Domagal-Goldman et al. 2014; Tian et al. 2014; Rameriz and Kaltenegger 2014; Wordsworth and Pierrehumbert 2014; Luger and Barns 2015; Harman et al. 2015; Gao et al. 2015; or see recent review by Meadows et al. 2018). These abiotic mechanisms of $\mathrm{O}_{2}$ production largely require UV photolysis of $\mathrm{H}_{2} \mathrm{O}$ followed by hydrogen escape, or the photolysis of $\mathrm{CO}_{2}$. The final amount of $\mathrm{O}_{2}$ in the atmosphere, however, will ultimately depend on the redox potential of the surface, making it vital to measure other indicators to put constraints on the redox budget of the planet (see Schaefer et al. 2016; Wordsworth et al. 2017). The additional detection of $\mathrm{CH}_{4} \mathrm{or}_{2}$ or constraints on $\mathrm{CO}_{2}$ or $\mathrm{CO}$ could eliminate the "false positive problem" (Domagal-Goldman et al. 2014), as does the inclusion of lightning which is thought to be ubiquitous in planetary atmospheres (Harman et al. 2018a). For most of Earth's early history, $\mathrm{O}_{2}$ levels were low, around $10^{-7}$ to $10^{-5}$ bar as constrained by geological evidence from mass independent sulfur isotope fractionation (Sect. 6). It is debated when oxygenic photosynthesis first evolved (Brocks et al. 1999; Planavsky et al. (2014a); French et al. 2015; Lalonde and Konhauser 2015; Gold et al. 2017). However, a permanent and relatively quick rise in atmospheric $\mathrm{O}_{2}$ seemingly occurred around $2.33 \mathrm{Ga}$, termed the Great Oxidation Event (Luo et al. 2016; Bekker et al. 2004).

Oxygenic photosynthesis requires a second photosystem to harvest electrons from water, suggesting that this evolutionary innovation postdates the origin of anoxygenic photosynthesis, which requires only one photosystem (Hohmann-Marriott and Blankenship 2011). However, once oxygenic photosynthesis evolved, it probably began to dominate ecosystems relatively quickly, because the required substrates (photons, water and $\mathrm{CO}_{2}$ ) are abundant. Hence there may be a strong evolutionary selection pressure in favor of this metabolism, maintaining the possibility that it also evolved elsewhere. $\mathrm{O}_{2}$ gas remains a primary observational goal on exoplanets (Meadows et al. 2018). However, oxygen only produces a significant absorption feature in the spectrum of a planet if its partial pressure is above $10^{-2}$ times present atmospheric levels (PAL) (Segura et al. 2003). Below this threshold also $\mathrm{O}_{3}$ becomes difficult to detect, although it has stronger absorption features than $\mathrm{O}_{2}$ (Kasting and Catling 2003). Hence the invention of oxygenic photosynthesis is not a sufficient condition for the detection of an aerobic biosphere. It also depends strongly on $\mathrm{O}_{2}$ sinks, i.e. fluxes of reducing gases and minerals to a planet's surface. There is extensive debate about when in Earth's history detectable amounts of $\mathrm{O}_{2}$ were present. Estimates of Proterozoic $\mathrm{O}_{2}$ levels range from $0.1 \%$ PAL to a maximum of $40 \%$ PAL (Canfield 2005, Kump 2008, Planavsky et al. 2014b). The presence of charcoals after $420 \mathrm{Ma}$ indicates $\mathrm{O}_{2}$ levels of at least $60 \%$ PAL and up to $160 \%$ PAL (Scott and Glasspool 2006, Kump 2008). See Lyons et al. (2014) for a comprehensive review of oxygen through Earth's history and Meadows (2018) for a review of oxygen as a biosignature target on exoplanets.

\section{2 $\mathrm{N}_{2}$ and $\mathrm{O}_{2}$ as Possible Geo-Biosignature}

Nitrogen gas $\left(\mathrm{N}_{2}\right)$ is largely of geological origin, but it has a dynamic biogeochemical cycle with multiple oxidation states, which has led to the idea that a long-term stable $\mathrm{N}_{2}-\mathrm{O}_{2}$ atmosphere may be indicative of aerobic lifeforms and even point to an active tectonic regime 
(Krissansen-Totton et al. 2016; Stüeken et al. 2016b; Lammer et al. 2019). These arguments are based on the premise that (a) $\mathrm{N}_{2}$ and $\mathrm{O}_{2}$ are in thermodynamic equilibrium and may ultimately be converted to nitrogen oxides by high energy processes, unless both of them are constantly replenished by life (Krissansen-Totton et al. 2016); (b) net burial of nitrogen proceeds mostly under anoxic conditions where oxidative weathering of crustal ammonium is suppressed, which implies that the rise of $\mathrm{O}_{2}$ also leads to a decrease in $\mathrm{N}$ burial and therefore a build-up of $\mathrm{N}_{2}$ in the atmosphere, provided that buried $\mathrm{N}$ becomes re-exposed to weathering by tectonic uplift (Stuieken et al. 2016b), and (c) $\mathrm{N}_{2}$ may be easily removed from the atmosphere on young anoxic planets with a weak magnetic field where cosmic radiation is strong, whereas most return fluxes of $\mathrm{N}_{2}$ to the atmosphere are biologically driven and proceed via nitrate or nitrite, which require the presence of $\mathrm{O}_{2}$ (Lammer et al. 2019). Of course, these deliberations are only valid for terrestrial planets in their respective habitable zone, but these are the class of planets where the conditions for life as we know it are most promising. The detection of an atmosphere with $\mathrm{N}_{2}$ and $\mathrm{O}_{2}$ as bulk gases and only a considerably lower share of $\mathrm{CO}_{2}$ most likely constitutes a geo-biosignature.

\section{Conclusions and Outlook}

The development and sustenance of habitable conditions on Earth depends on numerous geological, solar, and biological factors. Initially, the composition and volatile content of Earth's building blocks determined the amount of water and greenhouse gases that could be released and maintained after Moon formation. The release itself was in turn dependent on the longevity of the magma ocean phase (Sect. 2), which would have been a function of Earth's internal heat, i.e. its endowment of radioactive elements, planetary differentiation and gravitational contraction. Further, the accumulation of gases within the atmosphere may have been limited by stellar erosion, if the young Sun radiated more strongly in the XUV range than it does today and if the upper atmosphere was not sufficiently cooled by high levels of $\mathrm{CO}_{2}$ (Sect. 5). It is also conceivable that some volatiles were converted back into magma-soluble molecules (e.g. $\mathrm{N}_{2}$ to $\mathrm{NH}_{3}$ ) by atmospheric processes (Sect. 2). Direct evidence for photochemistry on the early Earth is archived in the sulfur isotope record (Sects. 6, 7) and possibly in the record of organic carbon isotopes (Sect. 7). The return flux of volatiles into the mantle may have been accelerated by the onset of plate tectonics, and the timing of this onset was probably determined by the degree of volatile loss during the magma ocean phase (Sect. 3). The emergence of life likely enhanced the drawdown of both $\mathrm{CO}_{2}$ and $\mathrm{N}_{2}$ while also affecting the redox state of the atmosphere through the production of $\mathrm{CH}_{4}$ and $\mathrm{O}_{2}$ (Sect. 4). These biological imprints have probably had a substantial effect on the evolution of our planet and may serve as biosignatures on other terrestrial worlds (Sect. 8).

Our review highlights the complex interplay between physical and chemical processes many of which are so far only poorly constrained. The future of this field of research will greatly benefit from new cross-disciplinary approaches.

Acknowledgements We thank the organizers of the ISSI workshop on Planetary Evolution 2018 for making this volume possible. Bernard Marty provided detailed, constructive comments that improved the manuscript.

Publisher's Note Springer Nature remains neutral with regard to jurisdictional claims in published maps and institutional affiliations. 
Open Access This article is licensed under a Creative Commons Attribution 4.0 International License, which permits use, sharing, adaptation, distribution and reproduction in any medium or format, as long as you give appropriate credit to the original author(s) and the source, provide a link to the Creative Commons licence, and indicate if changes were made. The images or other third party material in this article are included in the article's Creative Commons licence, unless indicated otherwise in a credit line to the material. If material is not included in the article's Creative Commons licence and your intended use is not permitted by statutory regulation or exceeds the permitted use, you will need to obtain permission directly from the copyright holder. To view a copy of this licence, visit http://creativecommons.org/licenses/by/4.0/.

\section{References}

V.S. Airapetian, A. Glocer, G. Gronoff, E. Hébrard, W. Danchi, Prebiotic chemistry and atmospheric warming of early Earth by an active young Sun. Nat. Geosci. 9(6), 452-455 (2016)

A. Anbar, Elements and evolution. Science 322, 1481-1483 (2008)

A. Anbar, Y. Duan, T.W. Lyons, G.L. Arnold, B. Kendall, R.A. Creaser, A.J. Kaufman, G.W. Gordon, C.T. Scott, J. Garvin, R. Buick, A whiff of oxygen before the Great Oxidation Event? Science 317(5846), 1903-1906 (2007)

G. Arney, S.D. Domagal-Goldman, V.S. Meadows, E.T. Wolf, E. Schwieterman, B. Charnay, M. Claire, E. Hébrard, M.G. Trainer, The pale orange dot: the spectrum and habitability of hazy Archean Earth. Astrobiology 16, 873-899 (2016). https://doi.org/10.1089/ast.2015.1422

G.N. Arney, V.S. Meadows, S.D. Domagal-Goldman, D. Deming, T.D. Robinson, G. Tovar, E.T. Wolf, E. Schwieterman, Pale orange dots: the impact of organic haze on the habitability and detectability of earthlike exoplanets. Astrophys. J. 836, 49 (2017). https://doi.org/10.3847/1538-4357/836/1/49

G. Arney, S.D. Domagal-Goldman, V.S. Meadows, Organic haze as a biosignature in anoxic Earth-like atmospheres. Astrobiology 18(3), 311-329 (2018). https://doi.org/10.1089/ast.2017.1666

G. Avice, B. Marty, Perspectives on atmospheric evolution from noble gas and nitrogen isotopes on Earth, Mars Venus. Space Sci. Rev. (2020). https://doi.org/10.1007/s11214-020-00655-0. 2020

G. Avice, B. Marty, R. Burgess, The origin and degassing history of the Earth's atmosphere revealed by Archean xenon. Nat. Commun. 8, 15455 (2017)

G. Avice et al., Evolution of atmospheric xenon and other noble gases inferred from Archean to Paleoproterozoic rocks. Geochim. Cosmochim. Acta 232, 82-100 (2018)

D. Babikov, Recombination reactions as a possible mechanism of mass-independent fractionation of sulfur isotopes in the Archean atmosphere of Earth. Proc. Azerb. Natl. Acad. Sci. 114(12), 3062-3067 (2017). https://doi.org/10.1073/pnas.1620977114

W. Bains, J.J. Petkowski, C. Sousa-Silva, S. Seager, Trivalent phosphorus and phosphines as components of biochemistry in anoxic environments. Astrobiology 19, 885-902 (2019). https://doi.org/10.1089/ast. 2018.1958

A. Bar-Nun, S. Chang, Photochemical reactions of water and carbon monoxide in Earth's primitive atmosphere. J. Geophys. Res., Oceans 88(C11), 6662-6672 (1983)

A. Bar-Nun, H. Hartman, Synthesis of organic compounds from carbon monoxide and water by UV photolysis. Orig. Life 9(2), 93-101 (1978)

P.H. Barry, D.R. Hilton, Release of subducted sedimentary nitrogen throughout Earth's mantle. Geochem. Perspect. Lett. 2, 148-159 (2016)

A. Bekker, H.D. Holland, P.-L. Wang, D. Rumble III., H.J. Stein, J.L. Hannah, L.L. Coetzee, N.J. Beukes, Dating the rise of atmospheric oxygen. Nature 427, 117-120 (2004)

E.A. Bell, P. Boehnke, T.M. Harrison, W.L. Mao, Potentially biogenic carbon preserved in a 4.1 billion-yearold zircon. Proc. Azerb. Natl. Acad. Sci. 112(47), 14518-14521 (2015)

R.A. Berner, Z. Kothavala, GEOCARB III: a revised model of atmospheric $\mathrm{CO}_{2}$ over Phanerozoic time. Am. J. Sci. 301, 182-204 (2001)

B.G. Bills, R.D. Ray, Lunar orbital evolution: a synthesis of recent results. Geophys. Res. Lett. 26(19), 30453048 (1999)

K.R. Birmingham, E. Füri, K. Lodders, B. Marty, Chemical and isotopic evolution of the early Solar System. Space Sci. Rev. 201, 25-48 (2020)

J.D. Blum, L.S. Sherman, M.W. Johnson, Mercury isotopes in Earth and environmental sciences. Annu. Rev. Earth Planet. Sci. 42(1), 249-269 (2014). https://doi.org/10.1146/annurev-earth-050212-124107

W.F. Bottke, D. Vokrouhlický, S. Marchi, T. Swindle, E.R.D. Scott, J.R. Weirich, H. Levison, Dating the Moon-forming impact event with asteroidal meteorites. Science 348(6232), 321-323 (2015)

B.P. Boudreau, D.E. Canfield, A provisional diagenetic model for $\mathrm{pH}$ in anoxic porewaters: application to the FOAM site. J. Mar. Res. 46(2), 429-455 (1988) 
E.S. Boyd, A.D. Anbar, S. Miller, T.L. Hamilton, M. Lavin, J.W. Peters, A late methanogen origin for molybdenum-dependent nitrogenase. Geobiology 9(3), 221-232 (2011)

J.A. Brandes, N.Z. Boctor, G.D. Cody, B.A. Cooper, R.M. Hazen, H.S. Yoder Jr., Abiotic nitrogen reduction on the early Earth. Nature 395, 365-367 (1998)

J.J. Brocks, G.A. Logan, R. Buick, R.E. Summons, Archean molecular fossils and the early rise of eukaryotes. Science 285, 1033-1036 (1999)

R. Buick, The earliest records of life on Earth, in Planets and Life: The Emerging Science of Astrobiology, ed. by W.T.I. Sullivan, J. Baross (Cambridge University Press, Cambridge, 2007), pp. 237-264

A. Burke, K.A. Moore, M. Sigl, D.C. Nita, J.R. McConnell, J.F. Adkins, Stratospheric eruptions from tropical and extra-tropical volcanoes constrained using high-resolution sulfur isotopes in ice cores. Earth Planet. Sci. Lett. 521, 113-119 (2019). https://doi.org/10.1016/j.eps1.2019.06.006

N.J. Butterfield, Oxygen, animals and aquatic bioturbation: an updated account. Geobiology 16(1), 3-16 (2018)

B. Byrne, C. Goldblatt, Diminished greenhouse warming from Archean methane due to solar absorption lines. Clim. Past 11(3), 559-570 (2015)

D.E. Canfield, The early history of atmospheric oxygen: homage to Robert M. Garrels. Annu. Rev. Earth Planet. Sci. 33, 1-36 (2005)

R.M. Canup, E. Asphaug, Origin of the Moon in a giant impact near the end of the Earth's formation. Nature 412(8), 708-712 (2001)

P. Cartigny, B. Marty, Nitrogen isotopes and mantle geodynamics: the emergence of life and the atmospherecrust-mantle connection. Elements 9(5), 359-366 (2013)

D. Catling, The great oxidation event transition. Treatise Geochem. 6, 177-195 (2014b)

D.C. Catling, K.J. Zahnle, C.P. McKay, Biogenic methane, hydrogen escape, and the irreversible oxidation of early Earth. Science 293(5531), 839-843 (2001)

B.D. Charnay, G. Le Hir, F. Fluteau, F. Forget, D.C. Catling, A warm or a cold early Earth? New insights from a 3-D climate-carbon model. Earth Planet. Sci. Lett. 474, 97-109 (2017)

M.W. Claire, D.C. Catling, K.J. Zahnle, Biogeochemical modelling of the rise in atmospheric oxygen. Geobiology 4(4), 239-269 (2006). https://doi.org/10.1111/j.1472-4669.2006.00084.x

M.W. Claire, J.F. Kasting, S.D. Domagal-Goldman, E.E. Stüeken, R. Buick, V.S. Meadows, Modeling the signature of sulfur mass-independent fractionation produced in the Archean atmosphere. Geochim. Cosmochim. Acta 141, 365-380 (2014)

H.J. Cleaves II., The prebiotic geochemistry of formaldehyde. Precambrian Res. 164(3-4), 111-118 (2008)

G.D. Cody, Transition metal sulfides and the origins of metabolism. Annu. Rev. Earth Planet. Sci. 32, 569599 (2004)

K.C. Condie, E. Beyer, E. Belousova, W.L. Griffin, S.Y. O’Reilly, U-Pb isotopic ages and Hf isotopic composition of single zircons: the search for juvenile Precambrian continental crust. Precambrian Res. 139(12), 42-100 (2005)

S.A. Crowe, C. Jones, S. Katsev, C. Magen, A.H. O’Neill, A. Sturm, D.E. Canfield, G.D. Haffner, A. Mucci, B. Sundby, D.A. Fowle, Photoferrotrophs thrive in an Archean ocean analogue. Proc. Natl. Acad. Sci. 105(41), 15938-15943 (2008)

S.O. Danielache, C. Eskebjerg, M.S. Johnson, Y. Ueno, N. Yoshida, High-precision spectroscopy of 32S, 33S, and 34S sulfur dioxide: ultraviolet absorption cross sections and isotope effects. J. Geophys. Res. 113(D17), 84-89 (2008). https://doi.org/10.1029/2007JD009695

S.O. Danielache, S. Hattori, M.S. Johnson, Y. Ueno, S. Nanbu, N. Yoshida, Photoabsorption cross-section measurements of 32S, 33S, 34S, and 36S sulfur dioxide for the B1B1-X1A1 absorption band. J. Geophys. Res. 117(D24), n/a-n/a (2012). https://doi.org/10.1029/2012JD017464

S.O. Danielache, S. Tomoya, A. Kondorsky, I. Tokue, S. Nanbu, Nonadiabatic calculations of ultraviolet absorption cross section of sulfur monoxide: isotopic effects on the photodissociation reaction. J. Chem. Phys. 140(4), 044319 (2014). https://doi.org/10.1063/1.4862429

N. Dauphas, J.F. Kasting, Low $\mathrm{pCO}_{2}$ in the pore water, not in the Archean air. Nature 474, E1-E1 (2011). https://doi.org/10.1038/nature09960

D.W. Deamer, The origin of cellular life, in Planets and Life: The Emerging Science of Astrobiology, ed. by W.T. Sullivan, J. Baross (Cambridge University Press, Cambridge, 2007), pp. 187-209

F. Delarue, F. Robert, K. Sugitani, R. Tartèse, R. Duhamel, S. Derenne, Nitrogen isotope signatures of microfossils suggest aerobic metabolism 3.0 Gyr ago. Geochem. Perspect. Lett. 7, 32-36 (2018)

B. Dhuime, A. Wuestefeld, C.J. Hawkesworth, Emergence of modern continental crust about 3 billion years ago. Nat. Geosci. 8(7), 552-555 (2015)

S.D. Domagal-Goldman, V.S. Meadows, M.W. Claire, J.F. Kasting, Using biogenic sulfur gases as remotely detectable biosignatures on anoxic planets. Astrobiology 11(5), 419-441 (2011). https://doi.org/10. 1089/ast.2010.0509 
S. Domagal-Goldman, A. Segura, M. Claire, T. Robinson, V. Meadows, Abiotic ozone and oxygen in atmospheres similar to prebiotic Earth. Astrophys. J. 792, 90 (2014)

P.C. Dos Santos, Z. Fang, S.W. Mason, J.C. Setubal, R. Dixon, Distribution of nitrogen fixation and nitrogenase-like sequences amongst microbial genomes. BMC Genomics 13(1), 162 (2012)

J.L. Eigenbrode, K.H. Freeman, Late Archean rise of aerobic microbial ecosystems. Proc. Natl. Acad. Sci. 103(43), 15759-15764 (2006)

L.T. Elkins-Tanton, Linked magma ocean solidification and atmospheric growth for Earth and Mars. Earth Planet. Sci. Lett. 271(1-4), 181-191 (2008)

L.T. Elkins-Tanton, Magma oceans in the inner solar system. Annu. Rev. Earth Planet. Sci. 40(1), 113-139 (2012)

Y. Endo, S. Danielache, Y. Ueno, S. Hattori, M.S. Johnson, N. Yoshida, H.G. Kjaergaard, Photoabsorption cross-section measurements of 32S, 33S, 34S and 36S sulfur dioxide from 190 to $220 \mathrm{~nm}$. J. Geophys. Res., Atmos. 120, 2546-2557 (2015). https://doi.org/10.1002/2014JD021671

Y. Endo, Y. Ueno, S. Aoyama, S.O. Danielache, Sulfur isotope fractionation by broadband UV radiation to optically thin $\mathrm{SO}_{2}$ under reducing atmosphere. Earth Planet. Sci. Lett. 453(C), 9-22 (2016). https://doi. org/10.1016/j.eps1.2016.07.057

Y. Endo, S.O. Danielache, Y. Ueno, Total pressure dependence of sulfur mass-independent fractionation by $\mathrm{SO}_{2}$ photolysis. Geophys. Res. Lett. 46(1), 483-491 (2019)

J. Farquhar, H. Bao, M. Thiemens, Atmospheric influence of Earth's earliest sulfur cycle. Science 289, 756759 (2000)

J. Farquhar, J. Savarino, S. Airieau, M.H. Thiemens, Observation of wavelength-sensitive mass-independent sulfur isotope effects during $\mathrm{SO}_{2}$ photolysis: implications for the early atmosphere. J. Geophys. Res. 106, 32829-32839 (2001)

J. Farquhar, M. Peters, D.T. Johnston, H. Strauss, A. Masterson, U. Wiechert, A.J. Kaufman, Isotopic evidence for Mesoarchaean anoxia and changing atmospheric sulphur chemistry. Nature 449(7163), 706709 (2007). https://doi.org/10.1038/nature06202

B. Fegley, R.G. Prinn, H. Hartman, G.H. Watkins, Chemical effects of large impacts on the Earth's primitive atmosphere. Nature 319(6051), 305-308 (1986)

K. Fennel, M. Follows, P.G. Falkowski, The co-evolution of the nitrogen, carbon and oxygen cycles in the Proterozoic ocean. Am. J. Sci. 305, 526-545 (2005)

M. Ferus, F. Pietrucci, A.M. Saitta, A. Knížek, P. Kubelík, O. Ivanek, V. Shestivska, S. Civiš, Formation of nucleobases in a Miller-Urey reducing atmosphere. Proc. Natl. Acad. Sci. 114(17), 4306-4311 (2017)

G. Feulner, The faint young Sun problem. Rev. Geophys. 50(2), RG2006 (2012). https://doi.org/10.1029/ 2011RG000375

D.T. Flannery, A.C. Allwood, M.J. van Kranendonk, Lacustrine facies dependence of highly 13C-depleted organic matter during the global age of methanotrophy. Precambrian Res. 285, 216-241 (2016)

D.T. Flannery, A.C. Allwood, R.E. Summons, K.H. Williford, W. Abbey, E.D. Matys, N. Ferralis, Spatiallyresolved isotopic study of carbon trapped in $\sim 3.43 \mathrm{Ga}$ Strelley Pool Formation stromatolites. Geochim. Cosmochim. Acta 223, 21-35 (2018)

J.J. Fortney, On the carbon-to-oxygen ratio measurement in nearby Sun-like stars: implications for planet formation and the determination of stellar abundances. Astrophys. J. Lett. 747(2), 2 (2012). https://doi. org/10.1088/2041-8205/747/2/L27

K.L. French, C. Hallmann, J.M. Hope, P.L. Schoon, J.A. Zumberge, Y. Hoshino, C.A. Peters, S.C. George, G.D. Love, J.J. Brocks, R. Buick, Reappraisal of hydrocarbon biomarkers in Archean rocks. Proc. Natl. Acad. Sci. 112(19), 5915-5920 (2015)

G. Fuchs, Alternative pathways of carbon dioxide fixation: insights into the early evolution of life? Annu. Rev. Microbiol. 65, 631-658 (2011)

E. Füri et al., Space Sci, Rev. (2020, this issue)

E. Füri, B. Marty, Nitrogen isotope variations in the Solar System. Nat. Geosci. 8(7), 515-522 (2015)

P. Gao, R. Hu, T.D. Robinson, L. Cheng, Y.L. Yung, Stability of $\mathrm{CO}_{2}$ atmospheres on desiccated M dwarf exoplanets. Astrophys. J. 806, 249 (2015)

J.B. Glass, F. Wolfe-Simon, J.J. Elser, A.D. Anbar, Molybdenum-nitrogen co-limitation in freshwater and coastal heterocystous cyanobacteria. Limnol. Oceanogr. 55(2), 667-676 (2010)

L.V. Godfrey, P.G. Falkowski, The cycling and redox state of nitrogen in the Archaean ocean. Nat. Geosci. 2, 725-729 (2009)

D.A. Gold, A. Caron, G.P. Fournier, R.E. Summons, Paleoproterozoic sterol biosynthesis and the rise of oxygen. Nature 543(7645), 420-423 (2017)

C. Goldblatt, K.J. Zahnle, Faint young Sun paradox remains. Nature 474(7349), E1-E1 (2011). https://doi. org/10.1038/nature09961

C. Goldblatt, M.W. Claire, T.M. Lenton, A.J. Matthews, A.J. Watson, K.J. Zahnle, Nitrogen-enhanced greenhouse warming on early Earth. Nat. Geosci. 2(12), 891-896 (2009) 
E.A. Goosmann, D.C. Catling, S.M. Som, W. Altermann, R. Buick, Eolianite grain size distributions as a proxy for large changes in planetary atmospheric density. J. Geophys. Res., Planets 123(10), 1-21 (2018)

D.O. Gough, Solar interior structure and luminosity variation. Phys. Sol. Var. 74, 21-34 (1981)

J.L. Grenfell, J.-M. Grießmeier, P. von Paris, A.B.C. Patzer, H. Lammer, B. Stracke et al., Response of atmospheric biomarkers to $\mathrm{NO}_{\mathrm{x}}$-induced photochemistry generated by stellar cosmic rays for Earth-like planets in the habitable zone of M dwarf stars. Astrobiology 12(12), 1109-1122 (2012)

J.P. Grotzinger, J.F. Kasting, New constraints on Precambrian ocean composition. J. Geol. 101, 235-243 (1993)

M. Guedel, The Sun in time: activity and environment. Living Rev. Sol. Phys. 4(1), 3 (2007). https://doi.org/ 10.12942/1rsp-2007-3

A. Guzmán-Marmolejo, A. Segura, E. Escobar-Briones, Abiotic production of methane in terrestrial planets. Astrobiology 13(6), 550-559 (2013). https://doi.org/10.1089/ast.2012.0817

I. Halevy, Production, preservation, and biological processing of mass-independent sulfur isotope fractionation in the Archean surface environment. Proc. Natl. Acad. Sci. 110(44), 17644-17649 (2013). https:// doi.org/10.1073/pnas.1213148110

K. Hamano, Y. Abe, H. Genda, Emergence of two types of terrestrial planet on solidification of magma ocean. Nature 497(7451), 607-610 (2013)

J.D. Haqq-Misra, S.D. Domagal-Goldman, P.J. Kasting, J.F. Kasting, A revised, hazy methane greenhouse for the Archean Earth. Astrobiology 8(6), 1127-1137 (2008)

C. Harman, E. Schwieterman, J. Schottelkotte, J. Kasting, Abiotic $\mathrm{O}_{2}$ levels on planets around F, G, K, and M stars: possible false positives for life? Astrophys. J. 812, 137 (2015)

C.E. Harman, R. Felton, R. Hu, S.D. Domagal-Goldman, A. Segura, F. Tian, J.F. Kasting, Abiotic $\mathrm{O}_{2}$ levels on planets around F, G, K, and M stars: effects of lightning-produced catalysts in eliminating oxygen false positives. Astrophys. J. 866(1), 1 (2018a). https://doi.org/10.3847/1538-4357/aadd9b

C.E. Harman, A.A. Pavlov, D. Babikov, J.F. Kasting, Chain formation as a mechanism for mass-independent fractionation of sulfur isotopes in the Archean atmosphere. Earth Planet. Sci. Lett. 496, 238-247 (2018b). https://doi.org/10.1016/j.eps1.2018.05.041

M.H. Hart, The evolution of the atmosphere of the Earth. Icarus 39, 23-39 (1978)

J.M. Hayes, Geochemical evidence bearing on the origin of aerobiosis, a speculative hypothesis, in Earth's Earliest Biosphere, ed. by J.W. Schopf (Princeton University Press, Princeton, 1983), pp. 291-301

J.M. Hayes, Global methanotrophy at the Archean-Proterozoic transition, in Early Life on Earth, ed. by S. Bengtson (Columbia University Press, New York, 1994), pp. 220-236

E. Hébrard, M. Dobrijevic, P. Pernot, N. Carrasco, A. Bergeat, K.M. Hickson et al., How measurements of rate coefficients at low temperature increase the predictivity of photochemical models of Titan's atmosphere. J. Phys. Chem. A 113(42), 11227-11237 (2009). https://doi.org/10.1021/jp905524e

I.M. Held, A.Y. Hou, Nonlinear axially symmetric circulations in a nearly inviscid atmosphere. J. Atmos. Sci. 37(3), 515-533 (2002)

C. Herzberg, K. Condie, J. Korenaga, Thermal history of the Earth and its petrological expression. Earth Planet. Sci. Lett. 292(1-2), 79-88 (2010)

A.M. Hessler, D.R. Lowe, R.L. Jones, D.K. Bird, A lower limit for atmospheric carbon dioxide levels 3.2 billion years ago. Nature 428(6984), 736-738 (2004)

K. Hinrichs, Microbial fixation of methane carbon at $2.7 \mathrm{Ga}$ : was an anaerobic mechanism possible? Geochem. Geophys. Geosyst. 3, U1-U10 (2002)

M.M. Hirschmann, Magma ocean influence on early atmosphere mass and composition. Earth Planet. Sci. Lett. 341-344, 48-57 (2012)

M.F. Hohmann-Marriott, R.E. Blankenship, Evolution of photosynthesis. Annu. Rev. Plant Biol. 62(1), 515548 (2011). https://doi.org/10.1146/annurev-arplant-042110-103811

H.D. Holland, The Chemical Evolution of the Atmosphere and Oceans. Chem. Evol. Atmos. Ocean (NorthHolland/Princeton University Press, Princeton, 1984), 583 pp. Price US 24.50 Pap. US 75.00 cloth

M. Homann, P. Sansjofre, M. Van Zuilen, C. Heubeck, J. Gong, B. Killingsworth, I.S. Foster, A. Airo, M.J. Van Kranendonk, M. Ader, S.V. Lalonde, Microbial life and biogeochemical cycling on land 3,220 million years ago. Nat. Geosci. 11(9), 665-671 (2018)

S.M. Hörst, C. He, M.S. Ugelow, A.M. Jellinek, R.T. Pierrehumbert, M.A. Tolbert, Exploring the atmosphere of neoproterozoic Earth: the effect of $\mathrm{O}_{2}$ on haze formation and composition. Astrophys. J. 858, 1-9 (2018). https://doi.org/10.3847/1538-4357/aabd7d

B.Z. Houlton, S.L. Morford, R.A. Dahlgren, Convergent evidence for widespread rock nitrogen sources in Earth's surface environment. Science 360(6384), 58-62 (2018)

C.H. House, J.W. Schopf, K.O. Stetter, Carbon isotopic fractionation by Archaeans and other thermophilic prokaryotes. Org. Geochem. 34, 345-356 (2003) 
R. Hu, S. Seager, W. Bains, Photochemistry in terrestrial exoplanet atmospheres. I. Photochemistry model and benchmark cases. Astrophys. J. 761, 166 (2012)

J.M. Husson, S.E. Peters, Atmospheric oxygenation driven by unsteady growth of the continental sedimentary reservoir. Earth Planet. Sci. Lett. 460, 68-75 (2017)

D.L. Huston, C.W. Brauhart, S.L. Drieberg, G.J. Davidson, D.I. Groves, Metal leaching and inorganic sulfate reduction in volcanic-hosted massive sulfide mineral systems: evidence from the paleo-Archean Panorama district, Western Australia. Geology 29(8), 687-690 (2001)

G. Izon, A.L. Zerkle, I. Zhelezinskaia, J. Farquhar, R.J. Newton, S.W. Poulton et al., Multiple oscillations in Neoarchaean atmospheric chemistry. Earth Planet. Sci. Lett. 431, 264-273 (2015). https://doi.org/10. 1016/j.eps1.2015.09.018

G. Izon, A.L. Zerkle, K.H. Williford, J. Farquhar, S.W. Poulton, M. Claire, Biological regulation of atmospheric chemistry en route to planetary oxygenation, in Proceedings of the National Academy of Sciences of the United States of America (2017)

D.J. Jacob, Introduction to Atmospheric Chemistry (Princeton University Press, Princeton, 1999). Retrieved from: https://press.princeton.edu/titles/6767.html

S.A. Jacobson, A. Morbidelli, S.N. Raymond, D.P. O'Brien, K.J. Walsh, D.C. Rubie, Highly siderophile elements in Earth's mantle as a clock for the Moon-forming impact. Nature 508, 84-87 (2014)

B. Johnson, C. Goldblatt, The nitrogen budget of Earth. Earth-Sci. Rev. 148, 150-173 (2015)

B.W. Johnson, C. Goldblatt, EarthN: a new Earth system nitrogen model. Geochem. Geophys. Geosyst. 19(8), 2516-2542 (2018)

D.T. Johnston, Multiple sulfur isotopes and the evolution of Earth's surface sulfur cycle. Earth-Sci. Rev. 106(1-2), 161-183 (2011). https://doi.org/10.1016/j.earscirev.2011.02.003

C.P. Johnstone, M. Güdel, I. Brott, T. Lüftinger, Stellar winds on the main-sequence II: the evolution of rotation and winds. Astron. Astrophys. 577(25), A28 (2015a). https://doi.org/10.1051/0004-6361/ 201425301

C.P. Johnstone, M. Güdel, T. Lüftinger, G. Toth, I. Brott, Stellar winds on the main-sequence I: wind model. Astron. Astrophys. 577, A27 (2015b). https://doi.org/10.1051/0004-6361/201425300

C.P. Johnstone, M. Güdel, H. Lammer, K.G. Kislyakova, Upper atmospheres of terrestrial planets: carbon dioxide cooling and the Earth's thermospheric evolution. Astron. Astrophys. 617, A107 (2018). https:// doi.org/10.1051/0004-6361/201832776

C.P. Johnstone, M.L. Khodachenko, T. Lüftinger, K.G. Kislyakova, H. Lammer, M. Güdel, Extreme hydrodynamic losses of Earth-like atmospheres in the habitable zones of very active stars. Astron. Astrophys. 624, L10 (2019). https://doi.org/10.1051/0004-6361/201935279

A.A. Kadik, N.A. Kurovskaya, Y.A. Ignat'ev, N.N. Kononkova, V.V. Koltashev, V.G. Plotnichenko, Influence of oxygen fugacity on the solubility of nitrogen, carbon, and hydrogen in $\mathrm{FeO}-\mathrm{Na}{ }_{2} \mathrm{O}-\mathrm{SiO}_{2}-\mathrm{Al}_{2} \mathrm{O}_{3}$ melts in equilibrium with metallic iron at $1.5 \mathrm{GPa}$ and $1400^{\circ} \mathrm{C}$. Geochem. Int. 49(5), 429-438 (2011)

Y. Kanzaki, T. Murakami, Estimates of atmospheric $\mathrm{CO}_{2}$ in the Neoarchean-Paleoproterozoic from paleosols. Geochim. Cosmochim. Acta 159, 190-219 (2015)

J.F. Kasting, Stability of ammonia in the primitive terrestrial atmosphere. J. Geophys. Res. 87(C4), 3091 (1982)

J.F. Kasting, D. Catling, Evolution of a habitable planet. Annu. Rev. Astron. Astrophys. 41(1), 429-463 (2003)

J.F. Kasting, J.C. Walker, Limits on oxygen concentration in the prebiological atmosphere and the rate of abiotic fixation of nitrogen. J. Geophys. Res., Oceans 86(C2), 1147-1158 (1981)

A.J. Kaufman, D.T. Johnston, J. Farquhar, A.L. Masterson, T.W. Lyons, S. Bates, A.D. Anbar, G.L. Arnold, J. Garvin, R. Buick, Late Archean biospheric oxygenation and atmospheric evolution. Science 317, 1900-1903 (2007)

P. Kharecha, J.F. Kasting, J. Siefert, A coupled atmosphere-ecosystem model of the early Archean Earth. Geobiology 3, 53-76 (2005)

M.A. Kipp, E.E. Stüeken, Biomass recycling and Earth's early phosphorus cycle. Sci. Adv. 3(11), eaao4795 (2017). https://doi.org/10.1126/sciadv.aao4795

M.C. Koehler, R. Buick, M.A. Kipp, E.E. Stüeken, J. Zaloumis, Transient surface ocean oxygenation recorded in the 2.66-Ga Jeerinah formation, Australia. Proc. Natl. Acad. Sci. 115(30), 7711-7716 (2018)

M.C. Koehler, R. Buick, M.E. Barley, Nitrogen isotope evidence for anoxic deep marine environments from the Mesoarchean Mosquito Creek formation, Australia. Precambrian Res. 320, 281-290 (2019)

J. Korenaga, Thermal evolution with a hydrating mantle and the initiation of plate tectonics in the early Earth. J. Geophys. Res., Solid Earth 116(12), 1-20 (2011)

J. Korenaga, Initiation and evolution of plate tectonics on Earth: theories and observations. Annu. Rev. Earth Planet. Sci. 41(1), 117-151 (2013) 
J. Krissansen-Totton, D.S. Bergsman, D.C. Catling, On detecting biospheres from chemical thermodynamic disequilibrium in planetary atmospheres. Astrobiology 16(1), 39-67 (2016). https://doi.org/10.1089/ ast. 2015.1327

K. Kritee, D.M. Sigman, J. Granger, B.B. Ward, A. Jayakumar, C. Deutsch, Reduced isotope fractionation by denitrification under conditions relevant to the ocean. Geochim. Cosmochim. Acta 92, 243-259 (2012)

M. Kuga, N. Carrasco, B. Marty, Y. Marrocchi, S. Bernard, T. Rigaudier, B. Fleury, L. Tissandier, Nitrogen isotopic fractionation during abiotic synthesis of organic solid particles. Earth Planet. Sci. Lett. 393, 2-13 (2014)

Y.N. Kulikov, E.F. Guinan et al., Atmospheric and water loss from early Venus atmospheric and water loss from early Venus. Planet. Space Sci. (2006). https://doi.org/10.1016/j.pss.2006.04.021

Y.N. Kulikov, H. Lammer, H.I.M. Lichtenegger, T. Penz, D. Breuer, T. Spohn, R. Lundin, H.K. Biernat, A comparative study of the influence of the active young Sun on the early atmospheres of Earth, Venus, and Mars. Space Sci. Rev. 129, 207-243 (2007)

L.R. Kump, The rise of atmospheric oxygen. Nature 451(7176), 277-278 (2008)

M. Kunze, M. Godolt, U. Langematz, J.L. Grenfell, A. Hamann-Reinus, H. Rauer, Investigating the early Earth faint young Sun problem with a general circulation model. Planet. Space Sci. 98, 77-92 (2014)

S.V. Lalonde, K.O. Konhauser, Benthic perspective on Earth's oldest evidence for oxygenic photosynthesis. Proc. Natl. Acad. Sci. 112(4), 995-1000 (2015)

H. Lammer, J.F. Kasting, E. Chassefière, R.E. Johnson, Y.N. Kulikov, F. Tian, Atmospheric escape and evolution of terrestrial planets and satellites. Space Sci. Rev. 139, 399-436 (2008)

H. Lammer, A.L. Zerkle, S. Gebauer, N. Tosi, L. Noack, M. Scherf, E. Pilat-Lohinger, M. Güdel, J.L. Grenfell, M. Godolt, A. Nikolaou, Origin and evolution of the atmospheres of early Venus, Earth and Mars. Astron. Astrophys. Rev. 26(1), 2 (2018). https://doi.org/10.1007/s00159-018-0108-y

H. Lammer, L. Sproß, J.L. Grenfell, M. Scherf, L. Fossati, M. Lendl, P.E. Cubillos, The role of $\mathrm{N}_{2}$ as a geobiosignature for the detection and characterization of Earth-like habitats. Astrobiology 19(7), 927-950 (2019). https://doi.org/10.1089/ast.2018.1914

H. Lammer, M. Leitzinger, P. Odert, C. Burger, C.M. Schäfer, D. Kubyshkina et al., Constraining the early evolution of Venus and Earth through atmospheric Ar, Ne isotope and bulk K/U ratios. Icarus 339, 113551 (2020). https://doi.org/10.1016/j.icarus.2019.113551

T. Lebrun, H. Massol, E. Chassefière, A. Davaille, E. Marcq, P. Sarda et al., Thermal evolution of an early magma ocean in interaction with the atmosphere. J. Geophys. Res. E, Planets 118(6), 1155-1176 (2013)

A. Lenardic, B. Foley The Craig, O. Neill, W.B. Moore, in Tectonic-Climate Coupling?: Variations in the Mean, Variations about the Mean, Variations in Mode, vol. 121 (2016), pp. 1-34

T.M. Lenton, Gaia and natural selection. Nature 394(6692), 439-447 (1998)

T.M. Lenton, R.A. Boyle, S.W. Poulton, G.A. Shields-Zhou, N.J. Butterfield, Co-evolution of eukaryotes and ocean oxygenation in the Neoproterozoic era. Nat. Geosci. 7(4), 257-265 (2014)

G. Libourel, B. Marty, F. Humbert, Nitrogen solubility in basaltic melt. Part I. Effect of oxygen fugacity. Geochim. Cosmochim. Acta 67(21), 4123-4135 (2003)

H.I.M. Lichtenegger, H. Lammer, J.-M. Grießmeier, Aeronomical evidence for higher $\mathrm{CO}_{2}$ levels during Earth's Hadean epoch. Icarus 210(1), 1-7 (2010)

S.J. Lock et al., The origin of the Moon within a terrestrial synestia. J. Geophys. Res., Planets 123(4), 910951 (2018)

R. Luger, R. Barns, Extreme water loss and abiotic $\mathrm{O}_{2}$ buildup on planets throughout the habitable zones of M dwarfs. Astrobiology 15, 119 (2015)

G. Luo, S. Ono, N.J. Beukes, D.T. Wang, S. Xie, R.E. Summons, Rapid oxygenation of Earth's atmosphere 2.33 billion years ago. Sci. Adv. 2(5), e1600134 (2016)

J.R. Lyons, Atmospherically-derived mass-independent sulfur isotope signatures, and incorporation into sediments. Chem. Geol. 267, 164-174 (2009)

T.W. Lyons, C.T. Reinhard, N.J. Planavsky, The rise of oxygen in Earth's early ocean and atmosphere. Nature 506, 307-315 (2014)

A. Mallik, Y. Li, M. Wiedenbeck, Nitrogen evolution within the Earth's atmosphere-mantle system assessed by recycling in subduction zones. Earth Planet. Sci. Lett. 482, 556-566 (2018)

B. Marty, L. Zimmermann, M. Pujol, R. Burgess, P. Philippot, Nitrogen isotopic composition and density of the Archean atmosphere. Science 342(6154), 101-104 (2013)

B. Marty, G. Avice, D.V. Bekaert, M.W. Broadley, Salinity of the Archaean oceans from analysis of fluid inclusions in quartz. C. R. Géosci. 350(4), 154-163 (2018)

E. Mason, M. Edmonds, A.V. Turchyn, Remobilization of crustal carbon may dominate volcanic arc emissions. Science 357(6348), 290-294 (2017)

H. Massol, K. Hamano, F. Tian, M. Ikoma, Y. Abe, E. Chassefière et al., Formation and evolution of protoatmospheres. Space Sci. Rev. 205(1-4), 153-211 (2016) 
A.L. Masterson, J. Farquhar, B.A. Wing, Sulfur mass-independent fractionation patterns in the broadband UV photolysis of sulfur dioxide: pressure and third body effects. Earth Planet. Sci. Lett. 306(3-4), 253-260 (2011). https://doi.org/10.1016/j.eps1.2011.04.004

T.A. Mather, D.M. Pyle, A.G. Allen, Volcanic source for fixed nitrogen in the early Earth's atmosphere. Geology 32(10), 905-908 (2004)

T.M. McCollom, J.S. Seewald, Carbon isotope composition of organic compounds produced by abiotic synthesis under hydrothermal conditions. Earth Planet. Sci. Lett. 243(1-2), 74-84 (2006)

T.M. McCollom, J.S. Seewald, Abiotic synthesis of organic compounds in deep-sea hydrothermal environments. Chem. Rev. 107, 382-401 (2007)

S.E. McGlynn, E.S. Boyd, J.W. Peters, V.J. Orphan, Classifying the metal dependence of uncharacterized nitrogenases. Front. Microbiol. 30(3), 419 (2012). https://doi.org/10.3389/fmicb.2012.00419

V.S. Meadows, C.T. Reinhard, G.N. Arney, M.N. Parenteau, E.W. Schwieterman, S.D. Domagal-Goldman, A.P. Lincowski, K.R. Stapelfeldt, H. Rauer, S. DasSarma, S. Hegde, Exoplanet biosignatures: understanding oxygen as a biosignature in the context of its environment. Astrobiology 18(6), 630-662 (2018)

V.S. Meadows, C.T. Reinhard, G.N. Arney, M.N. Parenteau, E.W. Schwieterman, S.D. Domagal-Goldman, A.P. Lincowski, K.R. Stapelfeldt, H. Rauer, S. DasSarma, S. Hegde, N. Narita, R. Deitrick, T.W. Lyons, N. Siegler, J. Lustig-Yaeger, Exoplanet biosignatures: understanding oxygen as a biosignature in the context of its environment. Astrobiology 18, 6 (2018)

M.P. Mehta, J.A. Baross, Nitrogen fixation at $92 \mathrm{C}$ by a hydrothermal vent archaeon. Science 314(5806), 1783-1786 (2006)

S. Mikhail, D.A. Sverjensky, Nitrogen speciation in upper mantle fluids and the origin of Earth's nitrogen-rich atmosphere. Nat. Geosci. 7(11), 816-819 (2014)

S.L. Miller, A production of amino acids under possible primitive Earth conditions. Science 117, 528-529 (1953)

K. Mishima, R. Yamazaki, M. Satish-Kumar, Y. Ueno, T. Hokada, T. Toyoshima, Multiple sulfur isotope geochemistry of Dharwar Supergroup, Southern India: late Archean record of changing atmospheric chemistry. Earth Planet. Sci. Lett. 464, 69-83 (2017)

J. Monteux, D. Andrault, H. Samuel, On the cooling of a deep terrestrial magma ocean. Earth Planet. Sci. Lett. 448, 140-149 (2016)

H. Moore, The isotopic composition of ammonia, nitrogen dioxide and nitrate in the atmosphere. Atmos. Environ. (1967) 11(12), 1239-1243 (1977)

S. Nabhan, M. Wiedenbeck, R. Milke, C. Heubeck, Biogenic overgrowth on detrital pyrite in ca. 3.2 Ga Archean paleosols. Geology 44(9), 763-766 (2016)

R. Navarro-González, M.J. Molina, L.T. Molina, Nitrogen fixation by volcanic lightning in the early Earth. Geophys. Res. Lett. 25(16), 3123-3126 (1998)

R. Navarro-González, C.P. McKay, D.N. Mvondo, A possible nitrogen crisis for Achaean life due to reduced nitrogen fixation by lightning. Nature 412(6842), 61-64 (2001a)

R. Navarro-González, C. Mckay, D. Nda Myondo, A possible nitrogen crisis for Archean life due to reduce nitrogen fixation by lighting. Nature 412(412), 61-64 (2001b)

R.W. Nicklas, I.S. Puchtel, R.D. Ash, P.M. Piccoli, E. Hanski, E.G. Nisbet, P. Waterton, D.G. Pearson, A.D. Anbar, Secular mantle oxidation across the Archean-Proterozoic boundary: evidence from V partitioning in komatiites and picrites. Geochim. Cosmochim. Acta 250, 49-75 (2019)

A. Nikolaou, N. Katyal, N. Tosi, M. Godolt, J.L. Grenfell, H. Rauer, What factors affect the duration and outgassing of the terrestrial magma ocean? Astrophys. J. 875(1), 11 (2019). https://doi.org/10.3847/ 1538-4357/AB08ED

E.G. Nisbet, N.V. Grassineau, C.J. Howe, P.I. Abell, M. Regelous, R.E.R. Nisbet, The age of Rubisco: the evolution of oxygenic photosynthesis. Geobiology 5, 311-335 (2007)

H. Ohmoto, Y. Watanabe, H. Ikemi, S.R. Poulson, B.E. Taylor, Sulphur isotope evidence for an oxic Archaean atmosphere. Nature 442(7105), 908-911 (2006). https://doi.org/10.1038/nature05044

C. O'Neill, V. Debaille, The evolution of Hadean-Eoarchaean geodynamics. Earth Planet. Sci. Lett. 406, 49-58 (2014)

S. Ono, Photochemistry of sulfur dioxide and the origin of mass-independent isotope fractionation in Earth's atmosphere. Annu. Rev. Earth Planet. Sci. 45(1), 301-329 (2017). https://doi.org/10.1146/annurevearth-060115-012324

S. Ono, J.L. Eigenbrode, A.A. Pavlov, P. Kharecha, D. Rumble III., J.F. Kasting, K.H. Freeman, New insights into Archean sulfur cycle from mass-independent sulfur isotope records from the Hamersley basin, Australia. Earth Planet. Sci. Lett. 213, 15-30 (2003)

S. Ono, A.R. Whitehill, J.R. Lyons, Contribution of isotopologue self-shielding to sulfur mass-independent fractionation during sulfur dioxide photolysis. J. Geophys. Res., Atmos. 118, 2444-2454 (2013) 
F. Ossa Ossa, A. Hofmann, J.E. Spangenberg, S.W. Poulton, E.E. Stüeken, R. Schoenberg, B. Eickmann, M. Wille, M. Butler, A. Bekker, Limited oxygen production in the Mesoarchean ocean. Proc. Natl. Acad. Sci. (2019). https://doi.org/10.1073/pnas.1818762116

K. Ozaki, E. Tajika, P.K. Hong, Y. Nakagawa, C.T. Reinhard, Effects of primitive photosynthesis on Earth's early climate system. Nat. Geosci. 11, 55-59 (2017). https://doi.org/10.1038/s41561-017-0031-2

M. Ozima, F.A. Podosek, Noble Gas Geochemistry (Cambridge University Press, Melbourne, 1983), https://doi.org/10.1017/S0016756800029587. x+367 pp. Price £40.00, U.S. \$79.50. ISBN 0-52123939-7. Geol. Mag. 121, 384

B.M. Packer, Sedimentology, paleontology, and stable-isotope geochemistry of selected formations in the 2.7-billion-year-old Fortescue Group, Western Australia. UCLA (1990), p. 187

K. Pahlevan, L. Schaefer, M.M. Hirschmann, Hydrogen isotopic evidence for early oxidation of silicate Earth. Earth and Planetary Science Letters 526, 15770 (2019)

A.P. Palya, I.S. Buick, G.E. Bebout, Storage and mobility of nitrogen in the continental crust: Evidence from partially melted metasedimentary rocks, Mt. Stafford, Australia. Chem. Geol. 281(3), 211-226 (2011)

R. Parai, S. Mukhopadhyay, Publisher correction: xenon isotopic constraints on the history of volatile recycling into the mantle. Nature 563(7732), E28 (2018)

D. Parkos, A. Pikus, A. Alexeenko, H.J. Melosh, HCN production via impact ejecta reentry during the late heavy bombardment. J. Geophys. Res., Planets 123(4), 892-909 (2018)

A.A. Pavlov, J.F. Kasting, Mass-independent fractionation of sulfur isotopes in Archean sediments: strong evidence for an anoxic Archean atmosphere. Astrobiology 2, 27-41 (2002)

A.A. Pavlov, J.F. Kasting, J.L. Eigenbrode, K.H. Freeman, Organic haze in Earh's early atmosphere: source of low-C-13 late Archean kerogens? Geology 29, 1003-1006 (2001)

R.O. Pepin, On the isotopic composition of primordial xenon in terrestrial planet atmospheres. Space Sci. Rev. 92, 371-395 (2000)

S. Péron, M. Moreira, Onset of volatile recycling into the mantle determined by xenon anomalies. Geochem. Perspect. Lett. 9, 21 (2018)

D.L. Pinti, K. Hashizume, Early life record from nitrogen isotopes, in Earliest Life on Earth: Habitats, Environments and Methods of Detection, ed. by S.D. Golding, M. Glikson (Springer, Berlin, 2010), pp. 183-205

J.P. Pinto, G.R. Gladstone, Y.L. Yung, Photochemical production of formaldehyde in Earth's primitive atmosphere. Science 210(4466), 183-185 (1980)

N.J. Planavsky, D. Asael, A. Hofmann, C.T. Reinhard, S.V. Lalonde, A. Knudsen, X. Wang, F.O. Ossa, E. Pecoits, A.J. Smith, N.J. Beukes, Evidence for oxygenic photosynthesis half a billion years before the Great Oxidation Event. Nat. Geosci. 7(4), 283-286 (2014a)

N.J. Planavsky, C.T. Reinhard, X. Wang, D. Thomson, P. McGoldrick, R.H. Rainbird, T. Johnson, W.W. Fischer, T.W. Lyons, Low Mid-Proterozoic atmospheric oxygen levels and the delayed rise of animals. Science 346(6209), 635-638 (2014b)

E.C. Pope, D.K. Bird, M.T. Rosing, Isotope composition and volume of Earth's Early Oceans. Proc. Natl. Acad. Sci. 109(12), 4371-4376 (2012)

M. Preiner, J. Xavier, F. Sousa, V. Zimorski, A. Neubeck, S. Lang, H. Greenwell, K. Kleinermanns, H. Tüysüz, T. McCollom, N. Holm, Serpentinization: connecting geochemistry, ancient metabolism and industrial hydrogenation. Life 8(4), 41 (2019). https://doi.org/10.3390/life8040041

G. Proskurowski, M.D. Lilley, J.S. Seewald, G.L. Früh-Green, E.J. Olson, J.E. Lupton, S.P. Sylva, D.S. Kelley, Abiogenic hydrocarbon production at Lost City hydrothermal field. Science 319(5863), 604607 (2008)

M. Pujol, B. Marty, P. Burnard, P. Philippot, Xenon in Archean barite: weak decay of 130Ba, mass-dependent isotopic fractionation and implication for barite formation. Geochim. Cosmochim. Acta 73, 6834-6846 (2009)

M. Pujol, B. Marty, R. Burgess, Chondritic-like xenon trapped in Archean rocks: a possible signature of the ancient atmosphere. Earth Planet. Sci. Lett. 308, 298-306 (2011)

R.M. Ramirez, L. Kaltenegger, The habitable zones of pre-main-sequence stars. Astrophys. J. Lett. 797(2), L25 (2014)

B. Rasmussen, Filamentous microfossils in a 3,235-million-year-old volcanogenic massive sulphide deposit. Nature 405(6787), 676-679 (2000)

J. Raymond, J.L. Siefert, C.R. Staples, R.E. Blankenship, The natural history of nitrogen fixation. Mol. Biol. Evol. 21(3), 541-554 (2004)

J.R. Reimink et al., No evidence for Hadean continental crust within Earth's oldest evolved rock unit. Nat. Geosci. 9(10), 777-780 (2016)

C.T. Reinhard, N.J. Planavsky, Mineralogical constraints on Precambrian pCO 2 . Nature 474, E1-E1 (2011). https://doi.org/10.1038/nature09959 
C.T. Reinhard, N.J. Planavsky, L.J. Robbins, C.A. Partin, B.C. Gill, S.V. Lalonde, A. Bekker, K.O. Konhauser, T.W. Lyons, Proterozoic ocean redox and biogeochemical stasis. Proc. Natl. Acad. Sci. 110(14), 5357-5362 (2013)

C.T. Reinhard, N.J. Planavsky, S.L. Olson, T.W. Lyons, D.H. Erwin, Earth's oxygen cycle and the evolution of animal life. Proc. Natl. Acad. Sci. 113(32), 8933-8938 (2016)

C.T. Reinhard, N.J. Planavsky, B.C. Gill, K. Ozaki, L.J. Robbins, T.W. Lyons, W.W. Fischer, C. Wang, D.B. Cole, K.O. Konhauser, Evolution of the global phosphorus cycle. Nature 541(7637), 386-389 (2017)

Ribas et al., Evolution of the solar activity over time and effects on planetary atmospheres. I. High-energy irradiances (1-1700Å). Astrophys. J. 622, 680 (2005). https://doi.org/10.1086/427977

D.H. Rothman, J.M. Hayes, R.E. Summons, Dynamics of the Neoproterozoic carbon cycle. Proc. Natl. Acad. Sci. 100(14), 8124-8129 (2003)

S. Rugheimer, L. Kaltenegger, Spectra of Earth-like planets through geological evolution around FGKM stars. Astrophys. J. 854, 19 (2018)

S. Rugheimer, L. Kaltenegger, A. Segura, J. Linsky, S. Mohanty, Effect of UV radiation on the spectral fingerprints of earth-like planets orbiting M dwarfs. Astrophys. J. 809, 57 (2015a)

S. Rugheimer, A. Segura, L. Kaltenegger, D. Sasselov, UV surface environment of Earth-like planets orbiting FGKM stars through geological evolution. Astrophys. J. 806, 137 (2015b)

M.J. Russell, W. Martin, The rocky roots of the acetyl-CoA pathway. Trends Biochem. Sci. 29(7), 358-363 (2004)

I.-J. Sackmann, A.I. Boothroyd, Our Sun. V. A bright young Sun consistent with helioseismology and warm temperatures on ancient Earth and Mars. Astrophys. J. 583(2), 1024-1039 (2002)

A. Salvador, H. Massol, A. Davaille, E. Marcq, P. Sarda, E. Chassefière, The relative influence of $\mathrm{H}_{2} \mathrm{O}$ and $\mathrm{CO}_{2}$ on the primitive surface conditions and evolution of rocky planets. J. Geophys. Res., Planets 122(7), 1458-1486 (2017)

J. Savarino, A. Romero, J. Cole-Dai, S. Bekki, M.H. Thiemens, UV induced mass-independent sulfur isotope fractionation in stratospheric volcanic sulfate. Geophys. Res. Lett. 30(21), 3645 (2003). https://doi.org/ 10.1029/2003GL018134

L. Schaefer, B. Fegley, Chemistry of atmospheres formed during accretion of the Earth and other terrestrial planets. Icarus 208(1), 438-448 (2010)

L. Schaefer, R. Wordsworth, Z. Berta-Thompson, D. Sasselov, Predictions of the atmospheric composition of GJ 1123b. Astrophys. J. 829(2), 63 (2016)

M. Scherf, M. Khodachenko, H. Lammer, I. Alexeev, C. Johnstone, M. Guedel, L. Tu, M. Blokhina, J. Tarduno, H. Lichtenegger, Y. Kulikov, The terrestrial paleo-magnetosphere and its implications on the origin and evolution of the nitrogen-dominated atmosphere, in EGU General Assembly Conference Abstracts, 20 (2018) p. 16210

M. Schidlowski, Carbon isotopes as biogeochemical recorders of life over 3.8 Ga of Earth history: evolution of a concept. Precambrian Res. 106, 117-134 (2001)

M. Schidlowski, J.M. Hayes, I.R. Kaplan, Isotopic inferences of ancient biochemistries: carbon, sulfur, hydrogen, and nitrogen, in Earth's Earliest Biosphere, ed. by J.W. Schopf (Princeton University Press, Princeton, 1983), pp. 149-186

J.A. Schmidt, M.S. Johnson, R. Schinke, Carbon dioxide photolysis from 150 to $210 \mathrm{~nm}$ : Singlet and triplet channel dynamics, UVspectrum, and isotope effects. Proc. Natl. Acad. Sci. 110(44), 17691-17696 (2013)

J.W. Schopf, K. Kitajima, M.J. Spicuzza, A.B. Kudryavtsev, J.W. Valley, SIMS analyses of the oldest known assemblage of microfossils document their taxon-correlated carbon isotope compositions. Proc. Natl. Acad. Sci. 115(1), 53-58 (2018)

P.A. Schroeder, A.A. McLain, Illite-smectites and the influence of burial diagenesis on the geochemical cycling of nitrogen. Clay Miner. 33(4), 539-546 (1998)

A.C. Scott, I.J. Glasspool, The diversification of Paleozoic fire systems and fluctuations in atmospheric oxygen concentration. Proc. Natl. Acad. Sci. USA 103, 10861-10865 (2006)

C. Scott, T.W. Lyons, A. Bekker, Y. Shen, S.W. Poulton, X. Chu, A.D. Anbar, Tracing the stepwise oxygenation of the Proterozoic ocean. Nature 452, 456-459 (2008)

S. Seager, W. Bains, J.J. Petkowski, Toward a list of molecules as potential biosignature gases for the search for life on exoplanets and applications to terrestrial biochemistry. Astrobiology 16(6), 1-21 (2016)

A. Segura, K. Krelove, J.F. Kasting, D. Sommerlatt, V. Meadows, D. Crisp et al., Ozone concentrations and ultraviolet fluxes on Earth-like planets around other stars. Astrobiology 3(4), 689-708 (2003). https:// doi.org/10.1089/153110703322736024

S.N. Silverman, S.H. Kopf, B.M. Bebout, R. Gordon, S.M. Som, Morphological and isotopic changes of heterocystous cyanobacteria in response to $\mathrm{N}_{2}$ partial pressure. Geobiology 17, 60-75 (2018)

N.H. Sleep, The Hadean-Archaean environment. Cold Spring Harb. Perspect. Biol. 2, a002527 (2010)

N.H. Sleep, G. Schubert, Plate tectonics through time. Evolution of the Earth 9, 145-169 (2007) 
N.H. Sleep, K. Zahnle, Carbon dioxide cycling and implications for climate on ancient Earth. J. Geophys. Res. 106(E1), 1373-1399 (2001)

A. Smirnov, D. Hausner, R. Laffers, D.R. Strongin, M.A. Schoonen, Abiotic ammonium formation in the presence of Ni-Fe metals and alloys and its implications for the Hadean nitrogen cycle. Geochem. Trans. 9, 5 (2008). https://doi.org/10.1186/1467-4866-9-5

M.A. Smit, K. Mezger, Earth's early $\mathrm{O}_{2}$ cycle suppressed by primitive continents. Nat. Geosci. 10(10), 788792 (2017)

V.S. Solomatov, Fluid dynamics of a terrestrial magma ocean, in Origin of the Earth and Moon, vol. 1, ed. by R. Canup, K. Righter (University of Arizona Press, Tucson, 2000), pp. 323-338

S.M. Som, D.C. Catling, J.P. Harnmeijer, P.M. Polivka, R. Buick, Air density 2.7 billion years ago limited to less than twice modern levels by fossil raindrop imprints. Nature 484(7394), 359-362 (2012)

S.M. Som, M. Sanjoy et al., Earth's air pressure 2.7 billion years ago constrained to less than half of modern levels. Nat. Geosci. 9(5), 1-5 (2016)

C. Sousa-Silva, S. Seager, S. Ranjan, J.J. Petkowski, Z. Zhan, R. Hu, W. Bains, Phosphine as a biosignature gas in exoplanet atmospheres. Astrobiology 20, 235-268 (2019)

B. Srinivasan, Barites: anomalous xenon from spallation and neutron-induced reactions. Earth Planet. Sci. Lett. 31, 129-141 (1976)

G. Stark, P.L. Smith, J. Rufus, A.P. Thorne, J.C. Pickering, G. Cox, High-resolution photoabsorption crosssection measurements of $\mathrm{SO}_{2}$ at $295 \mathrm{~K}$ between 198 and $220 \mathrm{~nm}$. J. Geophys. Res., Planets 104(E7), 16585-16590 (1999)

E.E. Stüeken, Nitrogen in ancient mud: a biosignature? Astrobiology 16(9), 730-735 (2016)

E.E. Stüeken, R. Buick, Environmental control on microbial diversification and methane production in the Mesoarchean. Precambrian Res. 304, 64-72 (2018)

E.E. Stüeken, D.C. Catling, R. Buick, Contributions to late Archaean sulphur cycling by life on land. Nat. Geosci. 5, 722-725 (2012)

E.E. Stüeken, R.E. Anderson, J.S. Bowman, W.J. Brazelton, J. Colangelo-Lillis, A.D. Goldman, S.M. Som, J.A. Baross, Did life originate from a global chemical reactor? Geobiology 11(2), 101-126 (2013)

E.E. Stüeken, R. Buick, B.M. Guy, M.C. Koehler, Isotopic evidence for biological nitrogen fixation by monitrogenase at 3.2 Gyr. Nature 520, 666-669 (2015)

E.E. Stüeken, M.A. Kipp, M.C. Koehler, R. Buick, The evolution of Earth's biogeochemical nitrogen cycle. Earth-Sci. Rev. 160, 220-239 (2016a)

E.E. Stüeken, M.A. Kipp, M.C. Koehler, E.W. Schwieterman, B. Johnson, R. Buick, Modeling $\mathrm{pN}_{2}$ through geological time: implications for planetary climates and atmospheric biosignatures. Astrobiology 16(12), 949-963 (2016b)

E.E. Stüeken, R. Buick, R.E. Anderson, J.A. Baross, N.J. Planavsky, T.W. Lyons, Environmental niches and metabolic diversity in Neoarchean lakes. Geobiology 15(6), 767-783 (2017)

D.P. Summers, S. Chang, Prebiotic ammonia from reduction of nitrite by iron (II) on the early Earth. Nature 365, 630-633 (1993)

D.Y. Sumner, I. Hawes, T.J. Mackey, A.D. Jungblut, P.T. Doran, Antarctic microbial mats: a modern analog for Archean lacustrine oxygen oases. Geology 43(10), 887-890 (2015)

F. Tabataba-Vakili, J.L. Grenfell, J.-M. Grießmeier, H. Rauer, Atmospheric effects of stellar cosmic rays on Earth-like exoplanets orbiting M-dwarfs. Astron. Astrophys. 585, A96 (2016). https://doi.org/10.1051/ 0004-6361/201425602

E. Tajika, T. Matsui, The evolution of the terrestrial environment. Orig. Earth 347-70 (1990)

E. Tajika, T. Matsui, Evolution of terrestrial proto- $\mathrm{CO}_{2}$ atmosphere coupled with thermal history of the Earth. Earth Planet. Sci. Lett. 113(1-2), 251-566 (1992)

M. Tang, K. Chen, R.L. Rudnick, Archean upper crust transition from mafic to felsic marks the onset of plate tectonics. Science 351(6271), 372-375 (2016)

T. Tashiro, A. Ishida, M. Hori, M. Igisu, M. Koike, P. Méjean, N. Takahata, Y. Sano, T. Komiya, Early trace of life from 3.95 Ga sedimentary rocks in Labrador, Canada. Nature 549(7673), 516-518 (2017)

M.H. Thiemens, History and applications of mass-independent isotope effects. Annu. Rev. Earth Planet. Sci. 34(1), 217-262 (2006). https://doi.org/10.1146/annurev.earth.34.031405.125026

M.H. Thiemens, S. Chakraborty, G. Dominguez, The physical chemistry of mass-independent isotope effects and their observation in nature. Annu. Rev. Phys. Chem. 63(1), 155-177 (2012). https://doi.org/10.1146/ annurev-physchem-032511-143657

C. Thomazo, M. Ader, J. Farquhar, P. Philippot, Methanotrophs regulated atmospheric sulfur isotope anomalies during the Mesoarchean (Tumbiana formation, Western Australia). Earth Planet. Sci. Lett. 279, 65-75 (2009a)

C. Thomazo, D.L. Pinti, V. Busigny, M. Ader, K. Hashizume, P. Phillippot, Biological activity and the Earth's surface evolution: insights from carbon, sulfur, nitrogen and iron stable isotopes in the rock record. C. R. Palevol 8, 665-678 (2009b) 
F. Tian, J.F. Kasting, H.L. Liu, R.G. Roble, Hydrodynamic planetary thermosphere model: 1. Response of the Earth's thermosphere to extreme solar EUV conditions and the significance of adiabatic cooling. J. Geophys. Res. E, Planets 113, 1-19 (2008a)

F. Tian, S.C. Solomon, L. Qian, J. Lei, R.G. Roble, Hydrodynamic planetary thermosphere model: 2. Coupling of an electron transport/energy deposition model. J. Geophys. Res. E, Planets 113, 1-13 (2008b)

F. Tian, K. France, J. Linsky, P. Mauas, M. Vieytes, High stellar FUV/NUV ratio and oxygen contents in the atmospheres of potentially habitable planets. Earth Planet. Sci. Lett. 385, 22-27 (2014)

D. Trail, E.B. Watson, N.D. Tailby, The oxidation state of Hadean magmas and implications for early Earth's atmosphere. Nature 480(7375), 79 (2011)

L. Tu, C.P. Johnstone, M. Güdel, H. Lammer, The extreme ultraviolet and X-ray Sun in time: high-energy evolutionary tracks of a solar-like star. Astron. Astrophys. 577, L3 (2015). https://doi.org/10.1051/0004 $-6361 / 201526146$

J.M. Tucker, S. Mukhopadhyay, Evidence for multiple magma ocean outgassing and atmospheric loss episodes from mantle noble gases. Earth Planet. Sci. Lett. 393, 254-265 (2014)

Y. Ueno, K. Yamada, N. Yoshida, S. Maruyama, Y. Isozaki, Evidence from fluid inclusions for microbial methanogenesis in the early Archaean era. Nature 440, 516-519 (2006)

T. Ushikubo et al., Lithium in Jack Hills Zircons: evidence for extensive weathering of Earth's earliest crust. Earth Planet. Sci. Lett. 272(3-4), 666-676 (2008)

M.J. Van Kranendonk, R. Hugh Smithies, A.H. Hickman, D.C. Champion, Review: secular tectonic evolution of Archean continental crust: interplay between horizontal and vertical processes in the formation of the Pilbara Craton, Australia. Terra Nova 19(1), 1-38 (2007)

P.M. Vitousek, D.N. Menge, S.C. Reed, C.C. Cleveland, Biological nitrogen fixation: rates, patterns and ecological controls in terrestrial ecosystems. Philos. Trans. R. Soc. B, Biol. Sci. 368(1621), 20130119 (2013). https://doi.org/10.1098/rstb.2013.0119

J.C.G. Walker, Carbon dioxide on the early Earth, in Origins of Life and Evolution of the Biosphere, vol. 16 (Kluwer Academic, Dordrecht, 1985), pp. 117-127

J.C.G. Walker, P.B. Hays, J.F. Kasting, A negative feedback mechanism for the long-term stabilization of Earth's surface temperature. J. Geophys. Res. 86(C10), 9776-9782 (1981)

W.L. Wang, J.K. Moore, A.C. Martiny, F.W. Primeau, Convergent estimates of marine nitrogen fixation. Nature 566(7743), 205-211 (2019)

D.J. Webb, Tides and the evolution of the Earth-Moon system. Geophys. J. R. Astron. Soc. 70(1), 261-271 (1982)

M.C. Weiss, F.L. Sousa, N. Mrnjavac, S. Neukirchen, M. Roettger, S. Nelson-Sathi, W.F. Martin, The physiology and habitat of the last universal common ancestor. Nat. Microbiol. (2016). https://doi.org/10.1038/ nmicrobiol.2016.116

C.G. Wheat, M.J. Mottl, M. Rudnicki, Trace element and REE composition of a low-temperature ridge-flank hydrothermal spring. Geochim. Cosmochim. Acta 66(21), 3693-3705 (2002)

A.R. Whitehill, S. Ono, Excitation band dependence of sulfur isotope mass-independent fractionation during photochemistry of sulfur dioxide using broadband light sources. Geochim. Cosmochim. Acta 94, 238253 (2012)

A.R. Whitehill, C. Xie, X. Hu, D. Xie, H. Guo, S. Ono, Vibronic origin of sulfur mass-independent isotope effect in photoexcitation of $\mathrm{SO}_{2}$ and the implications to the early Earth's atmosphere. Proc. Natl. Acad. Sci. USA 110, 17697-17702 (2013)

M.J. Whitehouse, D.J. Dunkley, M.A. Kusiak, S.A. Wilde, On the true antiquity of Eoarchean chemofossilsassessing the claim for Earth's oldest biogenic graphite in the Saglek Block of Labrador. Precambrian Res. 323, 70-81 (2019)

G.E. Williams, Geological constraints on the Precambrian history of Earth's rotation and the Moon's orbit. Rev. Geophys. 38(1), 37-59 (2000)

E.T. Wolf, O.B. Toon, Hospitable Archean climates simulated by a general circulation model. Astrobiology 13(7), 656-673 (2013)

R.D. Wordsworth, Atmospheric nitrogen evolution on Earth and Venus. Earth Planet. Sci. Lett. 447, 103-111 (2016)

R. Wordsworth, R. Pierrehumbert, Abiotic oxygen-dominated atmospheres on terrestrial habitable zone planets. Astrophys. J. Lett. 785(2), L20 (2014)

R.D. Wordsworth, L. Schaefer, R.A. Fischer, Redox evolution via gravitational differentiation on low mass planets: implications for biosignatures, water loss and habitability. Astron. J. 155, 5 (2017)

W.H. Yang, K.A. Weber, W.L. Silver, Nitrogen loss from soil through anaerobic ammonium oxidation coupled to iron reduction. Nat. Geosci. 5(8), 538-541 (2012)

Y.L. Yung, W.B. DeMore, Photochemistry of the stratosphere of Venus: implications for atmospheric evolution. Icarus 51, 199-247 (1982) 
K.J. Zahnle, Photochemistry of methane and the formation of hydrocyanic acid (HCN) in the Earth's early atmosphere. J. Geophys. Res. 91(D2), 2819-2834 (1986)

K.J. Zahnle, J.F. Kasting, J.B. Pollack, Evolution of a steam atmosphere during Earth's accretion. Icarus 74(1), 62-97 (1988)

K. Zahnle, J.B. Pollack, J.F. Kasting, Xenon fractionation in porous planetesimals. Geochim. Cosmochim. Acta 54, 2577-2586 (1990)

K.J. Zahnle, M.W. Claire, D.C. Catling, The loss of mass-independent fractionation in sulfur due to a Palaeoproterozoic collapse of atmospheric methane. Geobiology 4(4), 271-283 (2006)

K.J. Zahnle, L. Schaefer, B. Fegley, Earth's earliest atmospheres. Cold Spring Harb. Perspect. Biol. 2(10), a004895 (2010)

K.J. Zahnle, M. Gacesa, D.C. Catling, Strange messenger: a new history of hydrogen on Earth, as told by xenon. Geochim. Cosmochim. Acta 244, 56-85 (2019)

A.L. Zerkle, Biogeodynamics: bridging the gap between surface and deep Earth processes. Philos. Trans. R. Soc., Math. Phys. Eng. Sci. 376(2132), 20170401 (2018)

A.L. Zerkle, S. Mikhail, The geobiological nitrogen cycle: from microbes to the mantle. Geobiology 15(3), 343-352 (2017)

A.L. Zerkle, C.H. House, R.P. Cox, D.E. Canfield, Metal limitation of cyanobacterial $\mathrm{N}_{2}$ fixation and implications for the Precambrian nitrogen cycle. Geobiology 4(4), 285-297 (2006)

A.L. Zerkle, M.W. Claire, S.D. Domagal-Goldman, J. Farquhar, S.W. Poulton, A bistable organic-rich atmosphere on the Neoarchaean Earth. Nat. Geosci. 5, 359-363 (2012)

A.L. Zerkle, S.W. Poulton, R.J. Newton, C. Mettam, M.W. Claire, A. Bekker, C.K. Junium, Onset of the aerobic nitrogen cycle during the Great Oxidation Event. Nature 542(7642), 465-467 (2017)

P. Zmolek, X. Xu, T. Jackson, M.H. Thiemens, W.C. Trogler, Large mass independent sulfur isotope fractionations during the photopolymerization of 12CS 2 and 13CS 2. J. Phys. Chem. A 103(15), 2477-2480 (1999). https://doi.org/10.1021/jp9907140 